\title{
Comprehensive Physiology
}

Article type: Overview Article

Physiological role of vascular endothelial growth factors as homeostatic regulators

\section{Authors}

David O Bates ${ }^{1}$, Nicholas Beazley Long ${ }^{2}$, Andrew V Benest ${ }^{1}, \mathrm{Xi} \mathrm{Ye}^{3}$, Nikita Ved ${ }^{4}$, Richard P Hulse $^{1}$, Shaney Barratt ${ }^{5}$, Maria J Machado ${ }^{1}$, Lucy F Donaldson ${ }^{2}$, Steven J Harper ${ }^{6}$, Maria Peiris-Pages ${ }^{7}$, Domingo J Tortonese ${ }^{8}$, Sebastian Oltean $^{9}$, Rebecca R Foster $^{10}$

\section{Author Affiliations}

${ }^{1}$ Cancer Biology, Division of Cancer and Stem Cells, School of Medicine, University of Nottingham, Queen's Medical Centre, Nottingham NG2 7UH

${ }^{2}$ School of Life Sciences, University of Nottingham, Nottingham NG2 7UH

${ }^{3}$ Department of Pharmacology, University of Oxford, Mansfield Rd, Oxford OX1 3QT

${ }^{4}$ Department of Physiology, Anatomy and Genetics, University of Oxford, South Parks Road, Oxford OX1 3PT

${ }^{5}$ Academic Respiratory Unit, School of Clinical Sciences, University of Bristol, Bristol, UK ${ }^{6}$ School of Physiology, Pharmacology \& Neuroscience, Medical School, University of Bristol, UK

${ }^{7}$ Cancer Research UK Manchester Institute, The University of Manchester, Wilmslow Road, Manchester

${ }^{8}$ Centre for Comparative and Clinical Anatomy, University of Bristol, Southwell Street, Bristol BS2 8EJ, UK

${ }^{9}$ Institute of Biomedical \& Clinical Sciences, University of Exeter Medical School, Exeter, United Kingdom, EX1 2LU

${ }^{10}$ Bristol Renal, School of Clinical Sciences, University of Bristol, Dorothy Hodgkin Building, Whitson Street, Bristol, United Kingdom, BS1 3NY.

Author for correspondence. David Bates. Email. David.Bates@nottingham.ac.uk Running title. VEGFs as homeostatic regulators 


\begin{abstract}
The Vascular Endothelial Growth Factor family of proteins are key regulators of physiological systems. Originally linked with endothelial function, they have since become understood to be principal regulators of multiple tissues, both through their actions on vascular cells, but also through direct actions on other tissue types, including epithelial cells, neurons, and the immune system. The complexity of the 5 members of the gene family in terms of their different splice isoforms, differential translation, and specific localisations have enabled tissues to use these potent signalling molecules to control how they function to maintain their environment. This homeostatic function of VEGFs has been less intensely studied than their involvement in disease processes, development, and reproduction, but they still play a substantial and significant role in healthy control of blood volume and pressure, interstitial volume and drainage, renal and lung function, immunity, and signal processing in the peripheral and central nervous system. The widespread expression of VEGFs in healthy adult tissues, and the disturbances seen when VEGF signalling is inhibited support this view of the proteins as endogenous regulators of normal physiological function. This review summarises the evidence and recent breakthroughs in understanding of the physiology that is regulated by VEGF, with emphasis on the role they play in maintaining homeostasis.
\end{abstract}




\section{Introduction}

The Vascular Endothelial Growth Factor (VEGF) family of proteins are key regulators of physiological processes in development, growth, maintenance of lifelong health, and in many disease processes. Although originally described for the properties on vascular endothelial cells in 1989, the subsequent thirty years of research have identified multiple roles for these proteins in many different tissues, and many pathological states. Of the more than 65000 publications on the VEGFs since their discovery, the vast majority have focused on their role in abnormal states in humans. Their role in development has also been intensively investigated since VEGF-A became the first gene to be identified as heterozygously lethal when knocked out. However, right from the very beginning of VEGF research, a series of elegant papers from Harold Dvorak's laboratory demonstrated that VEGF-A was expressed, and at relatively high levels, in many normal tissues from healthy individuals. Despite this, VEGFs have been considered to be very good targets for development of inhibitors, both for VEGF-A itself, other members of the family, and for the VEGF receptors, particularly VEGF receptor 2 (VEGFR2). The fact that VEGF-A neutralizing antibodies were relatively safe as anticancer agents further supported the idea that VEGFs were disease causing agents in adults. However, relatively safe did not mean side effect free, and the consequences of anti-VEGF-A therapy (hypertension, proteinuria, dizziness, pain amongst others) do reinforce the concept that these proteins play a normal physiological role. It is widely accepted that there is a clear and important role for VEGFs in embryonic, and fetal development, growth during adolescence and in pregnancy, and the role of VEGFs in the angiogenesis associated with ovulation (in particular during endometrial and ovarian maturation, and during placentation) has been widely discussed. There are therefore areas of physiology associated with development where VEGFs have long been widely recognised as important. However, amongst the many thousands of papers describing VEGFs in disease states and development there is a growing body of literature that indicates that VEGFs play a physiological role in normal homeostasis outside that of the developmental pathway, and that disruption of this role by either too much or too little VEGF can result in pathology. In this review we will therefore focus on how VEGFs contribute to normal physiology in adult mammals, and in particular their role in maintaining a homeostatic environment conducive to healthy function. In particular we intend to discuss the roles of VEGF in maintaining normal physiological function through its activities as an angiogenic agent, but also as a regulator of vascular permeability, and 
the growing body of evidence that it is a cell survival factor, a nerve growth factor, and a signalling regulator that plays multiple roles in healthy systems, as well as being disrupted in disease states. Its role in the kidney, the lung, the nervous system, skeletal muscle, fat, and the retina are discussed as exemplars of where VEGF is a critical regulator of physiology. This is not exhaustive, and there are areas we have not covered (gut, heart, etc), but we hope that this provides a useful source to think about VEGF as a key regulator of normal as well as pathological states.

\section{VEGFs}

The VEGF family of proteins is encoded by five distinct genes in humans and other mammals. VEGF-A, the canonical member of the family, VEGF-B, VEGF-C, VEGF-D and Placental Growth factor (PIGF) are each encoded by multi-exon genes, and give rise to multiple splice variants. They are all secreted proteins, containing heparin binding domains, receptor binding domains, glycosylation sites, and intramolecular and intermolecular cysteine disulphide bonds. Each protein acts a dimer, and can act on two receptor families, the VEGFR and neuropilin families. VEGF Receptor 1 (VEGFR1) is also called fms-like tyrosine kinase (flt-1), VEGFR2 is also known as fetal liver kinase in the mouse, or Kinase Domain containing receptor (KDR) in the human, and VEGF receptor 3 (VEGFR3) is also known as flt-4. There are two neuropilin molecules, neuropilin 1 and neuropilin 2, which can bind both VEGF and the semaphorin family of proteins. Whilst VEGFRs have extensive signalling domains, and tyrosine kinase activity, the neuropilins have very short intracellular domains, which are able to recruit signalling molecules, but their ability to signal is less well described. They do however, play critical roles in VEGF signalling through their ability to control the activity of the VEGFRs, and are thus often referred to as co-receptors. (Figure 1).

\section{VEGF splicing}

All five VEGFs and the VEGFRs are generated as alternative splice variants. VEGF-A, also known as Vascular Permeability Factor (VPF) or Vasculotropin, is generated from 8 exons, the first four of which are constitutively spliced, and exon 8 is used in all splice isoforms. Exons 5, 6 and 7 are both cassette exons, and exons 6 and 7 can use alternate 5' splice sites to generate further isoforms. This results in formation of proteins of varying length as all these are coding exons (figure 2). Exon 8 has two different 3' splice sites, which leads to formation of two different families of the VEGF-A isoform. Use of the proximal splice site leads to the VEGF-A $A_{x x x}$ family, where $x x x$ denotes the 
number of amino acids, and use of a distal 3' splice site, 66 bases downstream results in the VEGF-A $A_{x x x} b$ family of isoforms. Exon 8 contains the stop codon, which is just 19nucleotides downstream of the splice site, so the VEGF-A $A_{x x x}$ isoforms have a translational stop before the distal splice site. There is also a stop codon 19nt downstream of the distal stop codon resulting in a mature mRNA with the same size open reading frame as the VEGF-A $A_{x x x}$ isoforms, and hence proteins of the same size. So VEGF-A $\mathrm{A}_{165}$ has a sister isoform, VEGF- $\mathrm{A}_{165} \mathrm{~b}$. It has also been demonstrated that under some circumstances the cell can choose to ignore the first stop codon, in a process known as post-translational readthrough. As the distal splice site is 66 bases from the proximal splice site, this results in use of the distal stop codon, and production of a protein that is 22 amino acids longer, or an extended VEGF-A, known as VEGF-Ax.

All the VEGF-A splice variants can bind to and activate the VEGFRs VEGFR1 and VEGFR3. The VEGF-A $A_{x x x}$ variants all induce cross phosphorylation of the 7 tyrosine residues in the $c$ terminal tail. However their ability to induce angiogenesis is variable, due to their different heparin binding ability. Exons 6 and 7 encode for heparin binding domains, and heparan sulfate acts as a facilitator for VEGFR2 activation (112). This means that VEGF-A $A_{165}$ more strongly induces VEGFR2 phosphorylation that VEGF-A $A_{121 .}$ The latter is also more freely diffusible, and secretion of the different splice variants allows a gradient of angiogenic proteins to be generated guiding cells to regions where vessel growth is needed (228). In contrast the VEGF-A $A_{x x x} b$ family, and the VEGF-Ax isoform, do not fully activate VEGFR2 and act as partial agonists, being able to only weakly and transiently activate phosphorylation of the tyrosine at amino acid $1175 \mathrm{f}$ the receptor (Y1175) but not Y1054. This means that VEGF-A $\mathrm{x}_{x x} b$ cannot stimulate proliferation, or branching of endothelial cells (136), or angiogenesis (293) (42), but still has the capability to prevent endothelial cell death (114). The mechanism behind this appears to be dependent on neuropilin binding, as VEGF- $A_{x x x} b$ does not bind neuropilin, which is required for recycling of the VEGFR2 to the surface instead of degradation by the endosome (17). Thus VEGF-A $A_{165} b$ acts as a competitive inhibitor of VEGF-A $A_{165}$ for angiogenesis, resulting in it having anti-angiogenic activity in circumstances where angiogenesis is VEGF- $A_{165}$ dependent (104).

VEGF-B, formed from 7 exons and has two splice variants, due to alternate 3' splice acceptor site in exon 6. The shorter isoform, VEGF-B ${ }_{167}$ is formed because this results in the stop codon in exon 6 being out of frame, and use of a stop codon early in 
exon 7, and the additional protein sequence confers heparin binding affinity. VEGF-B 186 lacks the heparin binding domain.

VEGF-C is generated from 8 exons, and exon 5 can be alternatively spliced. However, the function and expression of only the full length isoform has been investigated in any detail.

VEGF-D, also known as c-fos induced growth factor (FIGF) is generated from 7 exons as two splice variants, of which only one has been investigated in any detail.

PIGF is formed from 7 exons. This results in 3 known isoforms, PIGF1 (PIGF 131 ) PIGF2 $\left(\mathrm{PIGF}_{152}\right)$ and PIGF3 (PIGF 203$)$. In $\mathrm{PIGF}_{131}$, exon 6 is alternatively spliced out, and in PIGF$_{203}$, retention of intron 4 results in a 216 base insert, but this appears to happen in the absence of exon 6.

\section{VEGF gene transcription}

The VEGF-A gene is activated by a great number of transcription factors and is the convergent point for multiple diverse signalling pathways, which is reflective of diverse functions of VEGF. The vast majority of studies have focused on the role of hypoxia in VEGF-A control, as it is this hypoxia that is often thought to drive VEGF-A expression in disease states, and in remodeling (such as in exercise). The critical role of hypoxia in priming the transcriptional machinery necessary for massive upregulation of VEGF-A cannot be underestimated, and there are extensive reviews on the regulation of VEGF-A by hypoxia (e.g. (243)). However, in normal physiological tissues, VEGF-A is often widely expressed, and is regulated. This is likely due not solely to hypoxia but also to other conditions. While hypoxia depends to a great extent on the induction of the Hypoxia Inducing Factor (HIF) complex acting on hypoxia response elements in the VEGF-A promoter, alternative mechanisms of regulation are also apparent.

\section{HIF-Independent transcriptional regulation of VEGF.}

Deletion of the HRE (Hypoxia response element) from the VEGF-A promoter was sufficient to reduce basal VEGF-A mRNA by $40 \%$ in neural tissue, it remained unchanged in several others including cardiac, muscle and fibroblast cells. Under hypoxic conditions the difference between normal and HRE deletion was 75\%(210). Consequently this provides significant evidence that there is also HIF-independent regulation of VEGF-A, which at least is true for neuronal tissue and might contribute to disease conditions such as motoneurone disease (210). Of note, subsequent work 
demonstrated HIF-independent VEGF-A regulation, even in cardiac and skeletal tissue. Hypoxia and low glucose milieu, in peripheral ischaemia, increased expression of peroxisome-proliferator-activated receptor- $\gamma$ coactivator $1 \alpha$ (PGC-1 $\alpha)$ which in turn increased expression of oestrogen-related receptor- $\alpha$ (ERR- $\alpha)$. ERR- $\alpha$ directly binds to and activates the VEGF-A promoter (including the first intron sequence) and increases VEGF-A transcription(7). Hypoglycaemia, via protein kinase C (PKC)(212) and AP-1 and activation of C-Jun and JunB(266) also drives VEGF-A transcription.

VEGF-A promoter activity is also attenuated by several transcription factors. The prolinerich homeodomain protein $\mathrm{PRH} / \mathrm{H}$ hex binds to several sites in the VEGF-A and other promoters where it can repress several VEGFR genes, and also VEGF-A itself (199, 200). Furthermore the transcription factor SP1 binds to the E3 ligase Von Hippel Lindau (pVHL) which represses VEGF-A transcription(185) whereas normally SP1 activation is required for VEGF-A transcription. Several other well known tumour suppressor genes have been demonstrated to block VEGF-A transcription, including p53(301) and SMAD4(240).

\section{Shear stress}

The flow of blood through vessels is detected by endothelial cells by the sensing of shear stress - the physical force applied to a surface by a flowing viscous liquid such as plasma. This is therefore a key mechanism through which cells can sense their environment and maintain homeostasis. It has been increasingly recognised that increasing shear stress across the multiple cell types (including the endothelium) is a significant driving force for multiple genes, including VEGF-A $(94,158,213,268)$. In silico work suggested the presence of shear-stress response elements that are present in the promoters of many genes, including VEGF-A itself, and which appear to be present in several other signalling pathways which in turn regulate VEGF-A indirectly. Increased shear stress in the vasculature drives endothelial nitric oxide synthase (eNOS) upregulation(23, 38, 192, 247) and VEGF-A dependent angiogenesis (290, 291). Two processes that are intricately linked(23).

The Krüppel-like factor (KLF) family has been widely implicated in shear stress responses with KLF2 contributing to the regulation of shear stress regulated expression of several key angiogenic regulators, including VEGF-A (11). KLF2 activation is an essential component in regulating shear stress induced VEGF-A transcription, its own expression is enhanced by shear stress(61), and KLF2-knockdown is sufficient to reduce 
VEGF-A expression, and augmented KLF2 expression further enhances VEGF-A production following increased shear stress (61).

\section{Post-transcriptional factors that influence VEGF expression}

The activity of VEGF-A is also dependent on its post-transcriptional processing. VEGF-A is generated as contrasting isoform families by alternative splicing and translational repression. While some of the molecular mechanisms underlying this splicing control have begun to be identified (e.g. the splicing factor SRSF6 (198) appears to stimulate VEGF-A ${ }_{165} b$ expression whereas SRSF1 (197) and SRSF2 (179) regulate proximal splicing to generate VEGF- $A_{165}$, and this process appears to be controlled by activation of the splicing factor kinases SRPK1 (6) and Clk (171)) there is very little known about what controls this process in healthy physiology (e.g. in the kidney, in ovarian tissue or in the pituitary for instance).

The production of multiple mRNA transcripts, and environmental factor-dependent mRNA stability (hypoxia etc) is well described. However, the multi-layered posttranscriptional control of VEGF expression also extends to the translation of VEGF mRNA transcripts: from controlled mRNA binding protein- nuclear export and active polysome loading to a 3' UTR riboswitch. In most eukaryotic genes splice-isoform specific translation is proposed to be dependent on non-coding region interactions between the transcript itself and RNA-binding proteins, although RNA-RNA interactions also play a role in VEGF-A expression. Multiple miRNA target sites have now been identified in in the human VEGF 3'UTR as has a riboswitch sequence which is proposed to influence translation by a change in conformation folding of the mRNA molecule. (8)

\section{Homeostatic control of fluid balance}

VEGF and its receptors are found to be expressed in areas of the body where fluid balance is critically regulated - both locally, such as in the choroid plexus of the brain $(31,36)$, the choriocapillaris in the eye, or synovium $(79)$; and systemically, for instance in the kidney(31), in resistance vessels and in the gut(35). There therefore appears to be a role for VEGF in physiological maintenance of fluid homeostasis. Here we describe two different systems where this is exemplified - the kidney and the eye.

\section{Physiological role of vascular endothelial growth factors in the kidney}

The glomerulus is a VEGF rich environment where different members of the same family can balance their activities helping to achieve glomerular function homeostasis. All 
members of the family described above appear to have active roles in modifying or maintaining glomerular filtration barrier ultrastructures (fenestrations, glycocalyx and the sub-podocyte space) which appear to affect both small and large solute permeability. In disease there is imbalance in activity of these growth factors, but as we achieve greater understanding of the mechanisms behind these changes to the glomerular filtration barrier ultrastructure we can make significant clinical progress in restoring glomerular homeostasis.

VEGFs are highly expressed in the kidney glomeruli - the region of the renal cortex where fluid is filtered across the glomerular filtration barrier (GFB). VEGFs are produced by podocytes and play an important role in the development, maintenance and function of this highly specialised filtration barrier. This section will explore how these growth factors promote cross-talk within the glomerular filtration barrier and what the functional consequences of these are in health and disease.

\section{Podocyte production and endothelial cross talk}

The glomerular filtration barrier: The kidney filters blood to remove water and waste products whilst retaining essential larger proteins. In the human kidney there are approximately 1 million filtering units (nephrons), at the head of which are tangled balls of capillaries, called glomeruli, where the blood filtering occurs. The glomerular filtration barrier is highly specialised to allow copious volumes of water and small solutes to pass through unhindered yet retain the larger or more highly charged proteins. The glomerular endothelial cells (GEnC) form the capillaries and are highly fenestrated. These fenestrations are vital to allow up to $180 \mathrm{~L}$ of fluid to flow across in an adult kidney in 1 day, and are dependent upon the balance of VEGF-A isoforms $(73,208)$. Recently it was demonstrated that these fenestrations are not just empty holes that allow free flow of large proteins, but are plugged with a protective proteoglycan layer, the endothelial glycocalyx (e-GLX) (108) (figure 3). This not only plugs the fenestrations but also coats the endothelial cells of the glomeruli and all other vascular endothelial cells. The glomerular endothelial cells are supported by the glomerular basement membrane which is secreted by both podocytes and endothelial cells, is unusually thick and composed of laminin-521 ( $\alpha 5 \beta 2 \gamma 1)$, collagen $\alpha 3 \alpha 4 \alpha 5$ (IV), nidogens-1 and -2 , and the heparin sulphate proteoglycan, agrin (181). This layer also allows fluid to pass relatively unhindered but the complex structure and charged glycosaminoglycans (GAG) (chondroitin sulfate (285) as well as heparin sulfate) within it also help to restrict and 
repel larger proteins. Finally the glomerular basement membrane is surrounded by specialised epithelial cells called podocytes. Podocyte cells bodies protrude primary, secondary and tertiary foot processes that extend towards each other and interdigitate via a zipper-like structure. This zipper-like slit diaphragm is made from a number of proteins, many of which are specific to podocytes such as nephrin and NEPH-1 (10). Beyond the slit diaphragms, primary filtrate does not simply pass into Bowman's space , but instead passes through a labyrinth of cave-like structures that underlie the main body of the podocyte, called the subpodocyte space (SPS) (193). The SPSs have very narrow openings for a relatively large area and therefore this space is very restricted. Perfusion and $3 D$ reconstruction studies demonstrated that this space became even more restricted under physiological perfusion pressures (194). Labelled dextrans of moderate size (10KDa) were trapped in the SPS, but not small molecular weight molecules (450Da) suggesting that the SPS can restrict solute movement after passage through the slit diaphragm (232). It is well established that each layer plays an important role in protein filtration and breakdown of any layer in isolation can result in protein leak, and that all the layers are dependent upon VEGFs.

Glomerular VEGF-A: VEGF-A is highly expressed by human podocytes in situ in the developed, healthy adult kidney (15). The main role VEGF-A has been considered to be angiogenesis, yet there is no angiogenesis in healthy, adult glomeruli. Thus the role of VEGF-A in the healthy glomerulus is more complex. In human podocytes VEGF-A plays an autocrine role in podocyte survival (84) through its interaction with nephrin (85). Whether VEGFR-1 plays an important role in VEGF-A signalling is yet to be defined (84), however an autocrine loop for VEGF-A in podocytes has been shown to have clinical importance since antibodies that detected VEGF-A bound to its receptor (VEGFR-1 and 2) are increased in podocytes during the progression of glomerulonephritis (109). The importance of VEGF-A in glomerular endothelial maintenance $(74,75)$ has been demonstrated using podocyte specific and inducible VEGF-A knockout and overexpressing mice. VEGF-A is vital for glomerular filtration barrier maintenance in a highly dose sensitive manner. The complexity of the role of VEGF-A in diabetes was highlighted by a study from Dr Susan Quaggin's group whereby VEGF-A knock down in an early experimental model of diabetes was disastrous for glomerular injury. Even though elevated VEGF-A levels are associated with albuminuria in diabetes, VEGF-A is still necessary for glomerular function. Therefore a sledgehammer approach of VEGF 
manipulation to aid glomerular repair is unlikely to be effective, rather a more subtle approach that is still able to manage glomerular function and cyto-protection, is needed. Glomerular VEGF-A $A_{165} b$ : With the discovery of the anti-angiogenic sister isoforms of VEGF-A came physiological investigations within the kidney. VEGF- $\mathrm{A}_{165} \mathrm{~b}$ was originally discovered when exploring human renal samples from healthy individuals or those with renal carcinomas (21). It was revealed that VEGF- $A_{165} b$ was highly expressed by podocytes in the normal tissue, and in vitro studies in human podocytes pointed to a splicing switch of VEGF- $A_{x x x}$ to VEGF- $A_{x x x} b$ isoforms from a "developing" to a "differentiated" phenotype (51). VEGF-A $A_{x x \times b}$ expression in the developing human kidney was confirmed, and by adulthood VEGF- $A_{165} \mathrm{~b}$ expression in the kidney cortex was approximately equal to total VEGF-A (28). VEGF-A $A_{165} b$ was shown to competitively inhibit the actions of VEGF-A at VEGFR-2 (293). Interestingly, in Denys Drash syndrome, which is characterised by mutations in the gene WT-1, inducing glomerular endothelial cell damage, it seems that glomerular maturation is delayed. Podocyte profiles from these glomeruli resemble those of foetal profiles and predominantly express VEGF-A $A_{x x x}$ isoforms, suggesting defective VEGF-A splicing (239). VEGF- $A_{165} b$ expression at maturation in glomeruli is a feasible explanation for why high levels of glomerular VEGF-A expression do not induce angiogenesis. VEGF- $\mathrm{A}_{165} \mathrm{~b}$ was able to protect against significant proteinuria in diabetic nephropathy, even in the presence of the additional insult of overexpressed VEGF- $A_{165}$. VEGF- $\mathrm{A}_{165} \mathrm{~b}$ was also able to protect against a reduction in glomerular e-GLX depth, although it had no effect on fenestral density, probably because this was already significantly reduced in diabetes. VEGF$A_{165} b$ was also shown to restore e-GLX ex vivo in isolated diabetic rat glomeruli within $1 \mathrm{hr}$ (208).

Glomerular VEGF-C: Vascular endothelial growth factor C (VEGF-C) is also expressed by podocytes in human tissue in situ (131). VEGF-C is a lymphangiogenic growth factor, and yet there is no lymphangiogenesis within the glomeruli. This led to a similar question as podocyte VEGF-A expression - what is the purpose of VEGF-C in the glomerulus? VEGF-C acts on vascular endothelial cells as well as lymphatic endothelial cells and, intriguingly GEnC express VEGFR3 as well as VEGFR2 (86), some of the few endothelial cells that express both (all that do are fenestrated) (262). Human tissue culture studies demonstrated that VEGF-C acts on GEnC to restrict protein passage across monolayers (86). Interestingly VEGF-C did not phosphorylate VEGFR3, yet phosphorylated VEGFR2 over a longer timeframe. VEGF-C also induced an increase in 
intracellular calcium, but to a much lesser extent that VEGF-A. These data suggest that VEGF-C and VEGF-A act though the same receptor but with differing end points. Unexpectedly VEGF-C reduced the passage of labelled albumin through GEnC monolayers. Previously VEGF-C was shown to cause a rapid and sustained increase in hydraulic conductivity in frog mesenteric vessels (106) and overexpression caused increased blood vessel leakiness in the ear (229). VEGF-C was also shown to increase fenestration formation in blood vessels during neoangiogenesis and to increase macromolecular permeability, although not to the same extent as VEGF-A (40). Thus, the ability of VEGF-C to reduce endothelial cell leakiness appears to be specific to GEnC, at least in vitro. In isolated glomeruli we have shown that exogenous stimulation with VEGF-C for $1 \mathrm{hr}$ had no effect on glomerular albumin permeability. VEGF-A increased glomerular albumin permeability as expected yet this effect was abolished in the presence of VEGF-C (209). In GEnC in vitro VEGF-C promoted survival in a similar manner to VEGF-A. Using transgenic technology, VEGF-C was expressed specifically by podocytes in adult mice. Over a period of 3 weeks this had no effect on glomerular function and GEnC fenestration density remained the same (209). This is especially important when put into context with the actions of VEGF-A; podocyte-induced overexpression of VEGF-A led to a collapsing glomerulopathy and proteinuria $(75,282$, 283). Interestingly in GEnC VEGF-C was shown to induce de novo synthesis of e-GLX components whereas VEGF-A $A_{165}$ was shown to induce e-GLX shedding (83). Therefore VEGF-C appears to be able to maintain glomerular function and override the detrimental effects of VEGF-A. This may play an important role in physiology and has important clinical implications.

It is interesting to note that two members of the same family, VEGF- $\mathrm{A}_{165} \mathrm{~b}$ and VEGF-C, can override the effects of VEGF-A $A_{165}$ in glomerular function and both are associated with e-GLX restoration. Perhaps this is the key, not only to combating the development of albuminuria in diabetes, but also for targeted therapeutics in glomerular pathologies.

\section{Fenestral structure and function}

During the capillary loop stage of development of the glomerulus, the GEnC become flattened against the glomerular basement membrane and it is at this point that fenestrations form $(16,234)$. As stated above, GEnC are highly fenestrated with regular pores of approximately $60-70 \mathrm{~nm}$ diameter, which constitute $30-50 \%$ of the total cell surface area (16). Mathematical modelling suggests that the GEnC apply much less 
resistance to fluid flow across the vessel wall than the glomerular basement membrane or podocytes (65). These fenestrae are plugged with e-GLX (52) and therefore the fenestrae aid the flow of very large volumes of water and small solutes but restrict larger protein passage due to size and charge (201). Unusually for endothelial fenestrations, these are not supported by the structural protein PV-1, which appears to be lost after development, although may make a reappearance during progression of disease (121). Fenestrae are formed and maintained by VEGF-A, an important part of the cross talk communication between podocytes and endothelial cells. VEGF-A signals through VEGFR-2 to activate Rho/Rac and induce actin cytoskeletal rearrangement. This recruits PV-1 to the site of fenestration formation but this is subsequently removed (234). The role of VEGF-A in glomerular fenestration maintenance was highlighted by side effects of anti-VEGF-A antibodies in the treatment of cancer. Renal biopsies from these patients demonstrated thrombotic microangiopathies and a loss of GEnC fenestrations, associated with proteinuria (73). Even intravitreal injections of MaB VEGF-A were shown to localise to glomeruli in monkeys (271). This can have specific effects in disease, where renal function is disturbed due to alterations in VEGF signalling. For instance, in patients with pre-eclampsia, characterised by proteinuria associated with GEnC injury, including loss of fenestrations, by week 20 gestation (24) raised circulating soluble VEGFR1 can inhibit VEGF signalling. This phenotype was recapitulated using transgenic mouse models, whereby knock down of a single VEGF-A allele resulted in loss of GEnC fenestrations (75). In addition, in experimental studies where a bolus of either MaB antiVEGF-A or sVEGFR1 were given to mice, proteinuria developed associated with GEnC hypertrophy and loss of fenestrations (258). In renal biopsies from patients with early diabetic nephropathy there was an increase in GEnC fenestration density, correlated with increased glomerular filtration rate (GFR). In later stages of disease fenestrations were lost and GFR was reduced (87). Interestingly, loss of fenestrations was not only correlated with reduction in GFR, but also with increased albuminuria (288). This eas attributed to the loss of $\mathrm{e}-\mathrm{GLX}$ that plugs the fenestrations and coats the endothelial cells. VEGFs can manipulate both small and large solute permeability in glomeruli and this suggests that they can manipulate both GEnC fenestrations and its e-GLX.

\section{Sieving coefficients and hydraulic conductivity}

Glomerular function can be measured in terms of small and large solute permeability. GFR is a measure of small solute permeability of all functioning nephrons across two 
kidneys and can be estimated by creatinine clearance or directly measured using labelled inulin. However knowledge of single nephron GFR is also helpful since filtration rates can vary across the kidney whilst measurements at the single nephron level can be controlled. Similarly, large solute (macromolecular) permeability can be measured by urine albumin:creatinine ratios (UACR), yet this is not a direct measurement of glomerular function. Haemodynamic forces, blood flow and tubular reabsorption of proteins can all have an impact. By measuring glomerular sieving coefficients directly, these confounding factors can be bypassed.

Glomerular ultrafiltration coefficients: Glomerular ultrafiltration coefficient (LPA) is a measure of hydraulic conductivity across a single glomerulus. The effect of VEGF-A on rat glomerular ultrafiltration coefficient was first demonstrated by Salmon et al in 2006 (231) using a modified assay originally described by Savin et al (235). VEGF-A was shown to significantly increase glomerular $L p A / V_{i}$ (where $V_{i}$ is the initial volume of the glomerulus). In contrast when VEGF-A ${ }_{165} \mathrm{~b}$ was overexpressed specifically in podocytes it resulted in a reduction in $L p A / V_{i}$ in both homozygous and heterozygous mice which was associated with reduced fenestration density (220). Exogenous stimulation of isolated glomeruli with VEGF-A $A_{165} b$ led to a dose dependent decrease in $L p A / V_{i}$. Interestingly, when glomeruli were isolated from heterozygous VEGF- $A_{165} b$ overexpressing mice and stimulated with VEGF-A $\mathrm{A}_{165}, \mathrm{LpA} / \mathrm{V}_{\mathrm{i}}$ returned to baseline (220). Additional transgenic studies proved that podocyte-induced overexpression of VEGF$A_{165} b$ blocked the increase in glomerular $L p A / V_{i}$ in mice with podocyte-induced overexpression of VEGF- $A_{164}$ (the mouse pro-angiogenic isoform has 164 amino acids, whereas the human has 165)(207). Interestingly, overexpression of podocyte VEGF-A $A_{164}$ not only decreased the distance between fenestrae but also induced a reduction in SPS coverage of the glomerular capillary wall, demonstrating structural changes to account for reduced restriction to small solutes and water (207). Both of these ultrastructural changes were ameliorated with VEGF-A $\mathrm{A}_{165} \mathrm{~b}$ overexpression. That VEGFs can affect SPS suggests that they can modify the podocyte actin cytoskeleton directly.

Glomerular sieving coefficients: VEGF-A induces increased UACR $(75,282,283)$. These increases in UACR have been associated with increased GEnC fenestration density. Since fenestrations themselves are too large to restrict protein passage then it suggests the content of the fenestrations i.e. the e-GLX must have changed. Therefore it would be anticipated that VEGF-A would increase GSC due to loss or disruption of e-GLX. The first study to show that VEGF-A modified e-GLX in GEnC was in 2013 (83). This was an 
in vitro study on human cells, that demonstrated the functional importance of e-GLX on these cells in vitro, as also shown previously (248), but demonstrated that VEGF-A induced shedding of sulphated GAG from GEnC. In contrast VEGF-C increased the overall amount of sulphated GAG that were synthesised and increased de novo synthesis of an unsulphated GAG, hyaluronic acid (83). E-GLX depth, significantly reduced in Type I diabetic mice with early nephropathy, is restored by VEGF- $A_{165} b$ which also reduced UACR. Therefore it appears that VEGF-A $\mathrm{A}_{165} \mathrm{~b}$ and VEGF-C can compete with VEGF-A $A_{x x x}$ isoforms in the glomerulus to control water permeability and restrict macromolecular protein permeability and thus both VEGF- $\mathrm{A}_{165} \mathrm{~b}$ and VEGF-C signalling may have therapeutic implications in diabetic nephropathy and other glomerulopathies.

\section{Physiological role of VEGF-A in fluid and solute transport to and from the retina.}

The kidney is one example, but there are many tissues in which fluid flow into or out of it is both tightly regulated and not simple. In the retina, for instance, two different circulations, the retinal and the choroid, provide retinal blood flow, and maintaining fluid and solute transport to this tissue is critical for its function. Retinal pigmented epithelial (RPE) cells form a monolayer of epithelial cells on the outer surface of the retina, sitting on Bruch's membrane, and provide a selectively permeable barrier to ions, lipids and fluid between the outer retina and the choriocapillaris (CC), a dense area of fenestrated capillaries in the choroid (295). Paracellular flux is highly regulated by tight-junctions (TJs) including the family of claudins, occludin and the zonula occludens (ZO) family (295) in the cell membrane that allow the RPE layer its barrier function, immune privilege and selective transport between blood and the neural retina. As a vital component of the visual cycle, the apical surface of the RPE contain villi-like structures that are in close contact with rod and cone outer segments for the phagocytosis of photoreceptor outer segment discs (255), and for vitamin A transport (135).

Unlike the retinal vasculature, the choroidal plexus is fenestrated, to allow both fluid exchange and diffusion of nutrients such as glucose and fatty acids from the systemic circulation to the RPE, which in turn transports them to the outer retina. This transcellular movement is also utilised to transfer outer retinal waste products back to the choroidal circulation (289). The RPE basolaterally secretes VEGF-A, amongst many other growth factors and RPE-derived VEGF-A has an autocrine and paracrine role on the RPE and CC respectively. Conditional VEGF-A deletions result in a discontinuous RPE monolayer and an absent CC, (173) resulting in improper paracellular movement between the 
systemic and retinal circulation. RPE-derived VEGF-A is involved with maintaining the choroidal endothelium and stabilising choroidal fenestrae (230) This regulation is tightly coupled as the CC preferentially express VEGFR2 on the side facing the RPE. The maintenance of both the tightness of the RPE layer, and the fenestrations is dependent on expression of the anti-angiogenic isoform VEGF-A $A_{165} b$. RPE cells express both VEGF-A $A_{165}$ and VEGF-A $A_{165} b$ and while the former increases the permeability of RPE cell layers, the latter counteracts this, resulting in a tight junctional barrier which is disrupted in diabetic models, and by hyperglycaemia(278). VEGF- $A_{165} b$ is also able to exert a protective effect on both the RPE cells themselves, where it acts as a cytoprotective agent (167) reducing the effect of reactive oxygen species and oxidised cholesterol. VEGF- $A_{165} \mathrm{~b}$ is also likely to modulate the effect VEGF-A $A_{165}$ from inducing endothelial proliferation and excess fenestrations in the CC, as it does in the glomerulus, but this has yet to be confirmed (278).

The RPE also secretes Pigment-Epithelial derived Factor (PEDF), an anti-angiogenic, neuroprotective growth factor and also an endogenous VEGF antagonist, from the apical side (1). A balance between PEDF and VEGF expression is involved in CC and TJ maintenance and regulation, and therefore fluid and ion transport across the outer retinal barrier. When this balance is shifted in favour of VEGF, for example in the diabetic(2) or aged eye (149), there is increased TJ breakdown in the RPE, choroidal neovascularisation and aneurysm, all resulting in macromolecular leakage and fluid accumulation in the subretinal space.

\section{Cytoprotection and metabolism}

The crucial roles of VEGF proteins in the regulation of microvascular function in physiology and pathophysiology, has led to the use of VEGF-neutralising strategies becoming an important therapeutic tool in the treatment of diseases characterized by pathological angiogenesis and permeability. However many VEGF proteins are also cytoprotective for a large number of different cell types including endothelial, epithelial and neuronal cells. Systemic anti-VEGF-A therapies can therefore be associated with detrimental side effects: hypertension, proteinuria, bleeding, inflammation and intestinal perforation, which can be fatal(45). These detrimental side effects may in part be due to the loss of VEGF-induced cytoprotection and effects on metabolism. 


\section{Endothelial cytoprotection}

All VEGF family isoforms are ascribed endothelial cytoprotective properties. VEGF-A is a survival factor for newly formed vessels in development(92), early postnatal life $(5,92)$ and in adulthood (168). It acts as an endogenous survival factor for endothelial cells, as demonstrated by the effect of endothelial VEGF-A knockout, which results in lethality due to haemorrhage (156). Reduced plasma VEGF-A levels cause vascular attrition and functional abnormalities(258). The canonical endothelial cytoprotective signaling mechanism elicited by VEGF-A is through VEGFR2 activation of phosphatidylinositol-3 kinase (PI3K)/Akt signaling but the mechanism can differ depending on the VEGF-A splice variant and vascular bed in question. For example, in vitro assays indicate VEGF$A_{165}$-induced human vein umbilical vein endothelial cell (HUVEC) cytoprotection depends upon phosphatidylinositol-3 kinase (PI3K)/Akt signaling downstream of VEGFR2 and leads to upregulation of the anti-apoptotic protein B cell leukaemia/lymphoma-2 (Bcl-2) $(91,93)$, whereas VEGF-A 165 b/VEGFR2-induced HUVEC cytoprotection depends upon downstream ERK1/2 signaling(167). Differential expression of VEGF receptors (VEGFR1\&2) between the luminal and abluminal endothelial membranes, which is observed in pial and retinal but not lung endothelium, contributes to the complexity and pleiotropic nature of VEGF function including cytoprotection. In plial and retinal microvessels, Akt phosphorylation was observed following luminal but not parachymal application of VEGF-A $A_{165}$ through an action on VEGFR1(116). In addition PIGF and a PIGF/VEGF-A $A_{165}$ heterodimer are both cyto-protective for microvascular retinal endothelial cells through VEGFR1/Akt signalling(37, 116). PIGF can also promote uterine microvascular endothelial survival, along with VEGF-A and VEGF-C(303). VEGF$B$ is a vascular survival factor for endothelial cells, vascular pericytes and smooth muscle cells, but only under pathological conditions. It is thought that VEGF-B signals through VEGFR1 and co-receptor neuropilin-1, and promotes the expression of cytoprotective factors including serine/threonine kinase-1, VEGF-A, VEGF-C and hypoxia-inducible factor-1 $\alpha(300)$. Working through VEGFR3, VEGF-C activates ERK1/2 and both VEGF-C and VEGF-D are cytoprotective through VEGFR3 for lymphatic endothelial cells(169). In addition both VEGF-C and D bind to VEGFR2 and are cytoprotective for blood vessel endothelia. VEGF-D activates VEGFR2 differentially to VEGF-A 165 yet both factors promote HUVEC survival though PI3K/Akt signaling(127). 


\section{Retinal pigmented epithelial cytoprotection}

The retinal pigmented epithelium (RPE), as well as providing a barrier as discussed earlier, also provides trophic support to the photoreceptors. The accumulation of oxidative stress is thought to contribute to the progressive degeneration of the RPE in pathological conditions of the retina such as age-related macular degeneration (AMD)(292). VEGF-A is the major angiogenic factor which promotes ocular neovascularization and oedema(138). There is evidence that under normal conditions the endogenous anti-angiogenic VEGF-A splice variants (VEGF-A $A_{x x x} b$ ) predominate over the canonical angiogenic splice variants (VEGF-A $A_{x x x}$ ) and a switch to favour the angiogenic variants may underlie pathological retinal angiogenesis (216). In the neovascular (wet or exudative) form of AMD, choroidal vessels invade and disrupt the retina and vision of patients and pan-inhibition of VEGF-A protein has transformed therapy of the disease. However both VEGF- $A_{165}$ and VEGF- $A_{165} b$ variants are cytoprotective for RPE cells(167) and inhibiting all VEGF-A splice variants with bevacizumab or a neutralizing specific VEGF- $\mathrm{A}_{165} \mathrm{~b}$ antibody is cytotoxic $(167,254)$ and downregulates RPE Bcl-2 expression(142). A number of pre-clinical investigations and clinical reports have documented that intra-vitreal VEGF-A neutralization does not cause short-term functional abnormalities $(105,122,141,267)$. However a number of reports detail signs of retinal damage $(3,12,122,142,217)$. For example following a single dose of intra-vitreal bevacizumab in rabbits, the pro-apoptotic proteins b-cell lymphoma associated $x$ protein (bax), caspase -3 and caspase- 9 , were upregulated in the outer layers of the retina, in particular in the photoreceptors, as detected by immunohistochemistry (122), and electron microscopy revealed mitochondrial damage in the inner segment of the photoreceptors (122). Nuclear DNA fragmentation in the outer retinal layers, as detected by the TUNEL method was evident 14 days following single injection of anti-VEGF-A or three months following monthly injections (12). Whether the retinal toxicities from neutralizing VEGF-A arise due to the disruption of direct VEGF-Amediated cytoprotection or due to an indirect effect such as the disruption of VEGF-Amediated vascular perfusion is not clear to date. Evidence suggests long-term panVEGF-A neutralization in angiogenic ocular disease will have a detrimental effect on retinal health, whereas a more selective approach to neutralize the pathology-associated splice variants (VEGF- $A_{x x x}$ ), either by the specific antibody or pharmacological inhibition or by altering the balance of VEGF-A splice variants, may have the desired antiangiogenic action without the long-term detrimental cytotoxicity. 
RPE cells express other VEGF family isoforms, VEGF-B, C, D and PIGF and their respective role in ocular pathological angiogenesis is under investigation, although the possible roles in RPE cytoprotection is unclear and warrants further research. Neutralizing VEGF-A will remove the VEGF-A-mediated positive feedback on VEGF-A and VEGF receptor expression. Therefore it is likely that any cytoprotective action of other VEGFs that signal through VEGFR1 and 2 will also be negatively affected by antiVEGF therapy.

\section{VEGFs as multi-functional cytokines}

It has become increasingly clear over the last few years that VEGF is a multifunctional cytokine. It can act on many cell types, in many tissues to contribute roles that are outwith its original description as either a growth factor or permeability factor. In different cell types VEGFs can act as regulators of cell death, cell metabolism, cell communication and cell plasticity. Here we will investigate some of those processes that contribute to how the body can maintain functions as diverse as gas exchange in the lung, to learning and memory and pain detection.

\section{VEGF in the normal adult lung}

VEGFR1 and VEGFR2 are abundantly expressed within the vascular bed of the normal lung and are critical for normal development (244). They are also expressed by nonendothelial cells (non-ECs) including lung macrophages (236) (50) and alveolar epithelial type II (ATII) cells (81) (172) (176), although the exact role of VEGF in the alveolar compartment is not currently fully understood.

Neuropilins 1 and 2 (NRP 1 and NRP2) have been identified on several cell types within the lung including adult ECs (249) and ATII cells (177), although their role has not been fully defined. Neuropilins are transmembrane glycoproteins, which notably have a short cytoplasmic domain and as such are thought to transduce functional responses only when co-expressed with other receptors (196). Contrasting evidence exists however, suggesting that NRP1 is able to support VEGF-induced cellular signalling independent of VEGFR2 (99) and may have an independent role in the maintenance of normal lung structure (123). Of all the adult organs, VEGF-A mRNA expression is highest in the lung in both animals and humans (183) (27). VEGF-A and its receptors/co-receptors are expressed on both sides of the alveolar-capillary membrane (ACM) (68). The alveolar epithelium is considered to be the predominant source of VEGF-A in the lung $((27,172)$, 
(132), although a variety of cells such as smooth muscle cells, macrophages and ECs also express VEGF-A $(294,297))$.

Interestingly in health, VEGF-A expression within the lung is highly compartmentalised. Alveolar protein levels have been reported to be 500 times (2nM) that of plasma levels (132) and double that previously described as being required to induce biological effects in vivo (67). Yet paradoxically, the classical processes linked to VEGF-A activity (permeability, angiogenesis, mitogenesis) are extremely limited in the mature lung. This suggests an additional function for VEGF-A beyond development. It has been proposed that in the adult lung, VEGF-A may assist in maintaining a healthy lung, which crucially depends upon the compartmentalisation of VEGF-A through an intact ACM (178). Supporting this theory, VEGFR and co-receptors are found on both sides of the ACM (177) and in vitro VEGF-A acts as a survival and anti-apoptotic factor for both epithelial (189) (225) (148) and ECs in the normal lung (91) (93) (4). Furthermore, blockade of VEGF-A signalling induces an emphysema phenotype in several animal models (188) (134) (263) (272)). The magnitude of VEGF-A expression also appears to be tightly regulated in the normal lung; overexpression of VEGF-A in respiratory cells of adult mice also induces emphysematous change (153), pulmonary oedema and angiogenesis (29). VEGF-A may have a role in repair of the lung following injury, with the ability to induce proliferation of the systemic vasculature (157), growth of ATII cells (34) (277) and stimulate ATII cell surfactant production (48). Additionally, via its interaction with VEGFR1, VEGF-A appears to regulate apoptotic cell clearance by alveolar macrophages, another important process in the maintenance of tissue structure and function (137). VEGF-B, VEGF-C, VEGF-D and PIGF are all thought to contribute to the physiological development of the lung $(125,126)(97)(56))$. Their role in normal lung maintenance is less well understood but over-expression of PIGF in animal models appears to induce emphysematous changes (270). It has recently been shown that the isoform specific expression of VEGF-A is important for the development of pulmonary fibrosis both in vitro and in pre-clinical murine models. Differential expression of these isoforms may explain, in part, some of the apparently conflicting studies describing VEGF-A as both a protective and contributory factor. In this study ATII cell derived VEGF-A $A_{x x x}$ was critical for the development of fibrosis in a preclinical model of fibrosis with an inhibitory/regulatory function for VEGF- $A_{x x x} b$ isoforms(19). 


\section{VEGF and endothelial cell metabolism}

Vessel growth in normal as well as diseased tissues relies upon the generation of specialised endothelial cells that form the growing tip of vessel sprouts. These tip cells are followed by stalk cells - further specialised cells that proliferate and repress tip cell phenotypic alterations, such as filopodia and lamellipodia that can route-find and help the sprout grow. The remaining endothelial cells cover the lumen of blood vessels, but all endothelial cells are in close proximity to the high oxygen concentrations present in the blood. However, endothelial cells do not rely on an oxidative metabolism, but use a VEGF-A dependent glycolytic pathway for metabolism when they grow. Vessel branching is not affected by inhibition of mitochondrial respiration (54). Instead, glycolysis seems to be the predominant bioenergetic pathway for endothelial cells, as they are glucose-addicted and generate most of their ATP (85\%) via glycolysis (54). However, glycolysis with lactate production yields only two molecules of ATP per molecule of glucose, as compared to the 36 molecules of ATP generated via the oxidative metabolism of glucose.

Glycolysis can offer many benefits to endothelial cells. First of all, glycolysis generates ATP faster than oxidative phosphorylation, providing endothelial cells with the energy they need for the formation of new blood vessels and therefore allowing a more rapid restoration of the oxygen supply in the surrounding tissues. Secondly, the mobilization of glycolytic metabolites into secondary metabolic pathways for the generation of macromolecules for biomass synthesis during cell proliferation or for the production of reducing power for redox homeostasis may further contribute to a rapid vascularization. Third, by favouring glycolysis in the presence of oxygen, endothelial cells produce lower amounts of reactive oxygen species. Fourth, this way, the maximal amounts of oxygen are preserved for perivascular cells. Fifth, with an enhanced glycolysis, endothelial cells produce more lactate independently of oxygen, which in turn can act as a pro-angiogenic signalling molecule itself, further supporting vessel growth and branching (107). Sixth, glycolytic enzymes can be compartmentalized with F-actin and therefore arranged on a cellular matrix similar to an assembly line, where metabolic substrates are passed from one enzyme to the following one. Localizing the ATP production to those places where it is consumed, can be crucial. For instance, mitochondria, due to their structure and size, do not fit into narrow lamellipodia. Hence, compartmentalisation of glycolytic enzymes facilitates ATP supply in lamellipodia to fuel migration of tip endothelial cells (55). Finally, 
and most importantly, if endothelial cells would depend on oxidative glucose metabolism, the vascularisation of anoxic tissues would not be possible (69).

One of the rate-limiting steps in the glycolytic pathway is the conversion of fructose-6phosphate (F6P) to fructose-1,6-bisphosphate (F1,6P2), which is performed by 6phosphofructo-1-kinase (PFK-1). Phosphofructokinase-2/fructose-2,6-bisphosphatase (PFKFB) enzymes synthesize fructose-2,6-bisphosphate (F2,6P2), an allosteric activator of PFK-1 and a potent stimulator of glycolysis (275). In this context, VEGF-A directly modulates glycolysis via upregulation of the expression levels of the enzyme PFKFB3 (55), which is able to double the rate of glycolysis. In addition, genetic and pharmacological inhibition of PFKFB3 in endothelial cells reduces glycolysis and impairs vascular sprouting by decreasing both the proliferation of stalk cells, and by impeding the formation of filopodia in tip cells, thus preventing their migration $(55,237)$. PFKFB3 colocalises with F-actin, as also reported for other glycolytic enzymes (222). Increased PFKFB3 expression and glycolytic ATP production are detected in the lamellipodia compartment of migrating endothelial cells. In addition, stimulation of glycolysis by PFKFB3 overexpression induces the tip cell phenotype during vessel sprouting in vitro and in vivo $(55,237)$. Thus, a change in metabolism alone, in particular PFKFB3-driven glycolysis, is sufficient to promote tip cell behaviour giving raise to vessel outgrowth and branching.

Once a newly formed vessel is established, though, quiescent endothelial cells appear to re-program their glucose metabolism by downregulating glycolysis. Non-proliferative, contact-inhibited endothelial cells in vitro, which mimic the quiescent endothelium, are less glycolytic than proliferating endothelial cells (237). In accordance, endothelial cells under laminar shear stress as a surrogate of blood flow lower their glucose uptake, repress PFKFB3 expression and reduce glycolysis (62). Furthermore, in this scenario, expression and autocrine signalling of VEGF-A by endothelial cells seems to be necessary to sustain the integrity of the already established vascular network. Depletion of VEGF-A from the endothelium results in mitochondrial fragmentation and repression of mitochondrial respiration, oxygen consumption, glucose uptake, lactate production and triglyceride synthesis, resulting in increased autophagy and cell death via upregulation of the transcription factor FOXO1 (64). Thus, autocrine VEGF-A signalling is essential for the maintenance of a normal metabolic phenotype in endothelial cells. How VEGF-A can stimulate both oxidative metabolism and glycolytic metabolism is not 
known, but could depend on the status of the VEGFR receptor signalling, and the isoforms of VEGF-A being expressed.

\section{VEGF regulation of fatty acid uptake.}

VEGFs are also involved in uptake and transport of fatty acids across and into cells.

While medium ( $<12$ carbons) and short chain ( $<6$ carbons) fatty acids can freely diffuse across the phospholipid bilayer, long chain fatty acids (LCFA) require the assistance of membrane anchored proteins (101). Currently, there are four proposed mechanisms by which FA can pass through the plasma membrane into the cytoplasm of cells: 1 . Simple diffusion; 2. CD36 alone or in combination with the extracellular FA binding protein (FABP) bind onto FA to increase local FA concentration to facilitate passive diffusion; 3. CD36 may be able to actively transport FA into the cytoplasm; 4. Transportation by FA transporting proteins (FATP)(241). FATPs form an integral part of the LCFA uptake process and studies suggest the importance of VEGF-B signalling in the regulation of FATP expression on the endothelium (102). Overexpression of VEGF-B upregulates FATP3 and 4, while VEGF-B or Flt1 knockout downregulates FATPs in the endothelium of the heart (102). Indeed, the VEGF-B knockout animals have a reduced lipid uptake compared with the controls, suggesting the importance of VEGFR1 signaling and FATP in the transportation of FA in vivo (102).

VEGF-A mediated activation of VEGFR2 upregulates FA binding protein (FABP4) in the endothelium, which is involved in the trafficking and storage of FA $(72,88)$. Moreover, promotion of angiogenesis through VEGF-A or VEGFR2 has a protective role in obesity by reducing lipid uptake $(71,259)$. While VEGF-B is a weak angiogenic factor compared with VEGF-A, when VEGF-B is overexpressed in adipose tissues, it is capable of enhancing the microvascular density and reduce lipid deposition. The apparent VEGF-B induced angiogenesis has been postulated to function by displacing VEGF-A from VEGFR1, allowing it bind to VEGFR2 (224). The precise role of VEGF-B remains controversial. While some studies suggest VEGF-B inhibition reduces lipid uptake and increases insulin sensitivity in a mouse model of diabetes $(102,103)$, others showed VEGF-B overexpression did not provide these benefits (224) but improved insulin delivery in the adipose tissue (224) and plays a protective role during cardiac ischaemia (145). VEGF-B upregulation in transgenic mice appeared to induce cardiac hypertrophy, resulting in lowered blood pressure and heart rate. However, this was accompanied with 
altered lipid composition with excessive FA uptake, elevated ceramide production, mitochondrial damage and increased fatality of the transgenic animals (133).

\section{VEGF in skeletal muscle physiology and metabolism}

Skeletal muscle requires a dense and responsive vasculature. Capillaries feeding skeletal muscle have a thin endothelium, with cytoplasmic vesicles but few other organelles, with an intact basement membrane and smooth luminal and abluminal surfaces (70). This structure maximizes the contact surface area between capillaries and myofibres, which facilitates oxygen diffusion and removal of metabolites. Since metabolic demands in skeletal muscle are sensed via motor units, each unit exerts independent control of blood flow. This means that a highly hierarchical vascular structure is present in skeletal muscle. Larger arterioles (up to the third order: A3), possess vasomotor activity, control resistance and blood flow through the tissue. The more distal portion of the arteriolar tree (from the branch arteriole: A4, to the module inflow arteriole: A5) is involved in the regulation of capillary recruitment and blood flow distribution (191).

Altering metabolic demands, such as subjecting the highly plastic skeletal muscle to exercise training, results in hypoxia, which induces expression of VEGF-A $A_{165}$ in skeletal muscle cells. This results as both a vasodilator (147), enabling feeding arterioles (A3) to respond by sustained increase in blood flow, increased surface area by dilation of A4 and A5 arterioles and active angiogenesis(273), which increases surface area available for solute exchange in capillaries. One consequence of this is likely to be the reduction in blood flow seen in exercise when muscle specific VEGF is not available(146). However VEGF driven angiogenesis can also directly affect changes in skeletal muscle fibre type composition (287). These fibres differ in their function but also in mitochondrial content, expression of VEGF and capillary involvement (111). It has been proposed that VEGF is secreted to the interstitial space upon muscle contraction (111), but it is unclear the effect this exerts in the established vascular network.

In some disease states, such as peripheral arterial disease and diabetes, impaired VEGF signaling in skeletal muscle correlates with poor prognosis (180) (164) (30). VEGF has been identified as the main facilitator of angiogenesis in muscle, but the exact nature of this signaling is debatable, as both pro- and anti-angiogenic isoforms of VEGF are generated in response to ischemia, depending on the metabolic status of the individual people with metabolic dysfunction are more likely to generate anti-angiogenic isoforms of 
VEGF in response to ischemia, thus exacerbating the problem and contributing to peripheral, and potentially coronary, arterial disease(139). It has recently been shown that VEGF is essential in controlling arterialization and, thus, distribution of blood flow through the tissue (204) (256).

Using targeted deletion of VEGF in specific cell types, studies in animal models have elucidated the importance of VEGF signaling in skeletal muscle, both in exercise and disease. VEGF of endothelial origin seems to be necessary for EC survival since VEGFECKO mice display significant endothelial dysfunction, even with levels of circulating VEGF similar to their wild-type littermates (156). VEGF of skeletal muscle origin was found to be essential for the maintenance of capillary-to-fibre ratio and capillary density (205). Capillary rarefaction that occurred as a result of depleted muscle-specific VEGF was also found to contribute to augmented fasting glucose turnover. This was sufficient to induce muscle insulin resistance in lean mice (30). A reduction of over $90 \%$ in muscle VEGF protein severely hindered maximal running speed and exercise performance in mice (205). Olfert and colleagues have also found that myocyte-derived VEGF is essential for muscle capillary adaptation to exercise training (206). However, myocytederived VEGF is not the sole contributor of skeletal muscle adaptation to exercise. Mice where VEGF has been knocked-down in adipose tissue exhibit increased insulin sensitivity and impaired endurance running, probably due to blunted transport of lipid stores (299). Furthermore, after exercise, a lack of continued training (detraining) results in a reduction of vasculature, but VEGF is still maintained high. Studies have suggested that this might be a consequence of over-expression of anti-angiogenic factors such as TSP1, but a role for VEGF-A ${ }_{165} b$ has not yet been considered (203). Detailed studies of the differing effects between autocrine and paracrine VEGF signaling in muscle are going to be necessary to be able to fully understand how VEGF controls both response to exercise, and control of metabolic demand in both healthy patients and in ischemic disease.

\section{Control of function in the nervous system}

Since its original discovery the role of VEGF in the nervous system has been clear, but perhaps underappreciated. From angiogenic control of pituitary function, to its role as a regulator of hormonal release, synaptic plasticity and pain sensations, it is perhaps the neuronal aspects of VEGF function that are most overlooked in normal physiology. Here we identify some of the key aspects of VEGF in the nervous system. 


\section{Pituitary function}

VEGF-A was first isolated and purified by Napoleone Ferrara, one of the co-discoverers of VEGF, from pituitary folliculostellate cells (FSC) (157), indicating that the pituitary can be in charge of the regulation of its own vasculature. FSC are non-endocrine cells that form a three-dimensional network throughout the pituitary and can modulate the function of endocrine cells in a paracrine manner. These cells have been shown to display a high degree of plasticity, and in animals that change their physiology with season (e.g. reproduction, fur growth, horn growth etc), FSC demonstrate overt ultrastructural changes and varied number of adherens junctions across the year in response to seasonal changes in photoperiod. (46). Moreover, we have recently shown that these changes are accompanied by a significant increase in the density of FSC within the pars distalis of the pituitary gland during the long days of summer (41). It was thus surprising that the production of VEGF-A was reported to remain unchanged under different photoperiods (124), and the role of VEGF-A production by FSC in pituitary function has gone undiscovered for nearly 30 years.

In vertebrates, the pituitary gland plays a key role in maintaining homeostasis by means of a tightly regulated secretion of hormones that control a variety of functions such as metabolism, the response to stress, body growth, reproduction and lactation. This organ comprises two parts of different embryological origin that are fused during development, a glandular part referred to as the adenohypophysis or anterior pituitary, and a neural part known as the neurohypophysis, of which its major component is also sometimes referred to as the posterior pituitary. The glandular component is composed of three distinctive regions: the pars tuberalis, the pars distalis and the pars intermedia. The neural component contains fibres originating in the hypothalamus and includes the neural stalk and the neural lobe, or pars nervosa (96). A major difference with regard to hormone output between the glandular and neural part of the pituitary, is that whereas the former secretes homones produced locally, the latter releases hormones produced in hypothalamic nuclei. Because the local production of hormones within the pituitary gland relies on stimulatory and inhibitory hypothalamic signals, communication between the brain and pituitary for the delivery of those signals is of fundamental importance to ensure normal control of pituitary function. In mammals, this communication is achieved by means of an elegant portal vascular system that also ensures inter-communication among the different parts of the pituitary. The hypothalamic-pituitary portal system originates in the superior (or anterior, depending on species) hypophysial artery, which 
will give rise to a proximal primary capillary plexus between the median eminence and the pituitary stalk from where the long portal vessels arise (218). These portal vessels carry the blood that flows from the brain to the pars distalis (113). The inferior (or posterior) hypophysial artery supplies the pars nervosa, and in some species also generates a more distal capillary plexus with short portal vessels that primarily supply the region of the pars distalis neighbouring neural tissue(95). Thus, the vasculature of the pars distalis of the pituitary gland is deprived of arterial vessels and comprises a secondary capillary plexus that is entirely composed of veins.

Using the sheep as the experimental model, a detailed examination of the origin of the long portal vessels revealed that branches from the proximal capillary plexus cross the pars tuberalis before penetrating into the neural component of the pituitary stalk, and then loop to return to the pars tuberalis from where they continue into the pars distalis as long vessels (53). This glandular-neural intra-pituitary communication is likely to have an important physiological role because: 1) the pars tuberalis is the tissue responsible for annual time measurement; 2) the neural stalk contains a high density of glial-type foliculostellate cells; and 3) the pars distalis is the major source of pituitary hormones that control body functions. Therefore, it can be anticipated that regulation of the hypothalamic-pituitary portal system will have an impact on the multiple systems controlled by the pituitary gland. In support of this prediction, when the expression of specific VEGF-A isoforms was investigated, it became apparent that the output of VEGFA subtypes is dramatically affected by photoperiod. Indeed, the pro-angiogenic isoforms of VEGF-A, VEGF-A $A_{x x x}$, are upregulated during the long days of summer at the expense of a decrease in the anti-angiogenic variants, VEGF-A $A_{x x x} b$. Conversely, during the short days of winter the anti-angiogenic VEGF- $A_{x x x} b$ variant is upregulated at the expense of the proangiogenic VEGF-A $A_{x x x}$ variant (41). This seasonally regulated differential expression of VEGF-A isoforms results from alternative splicing of a single VEGF-A gene, and leads to a remarkable alteration in the pituitary microvasculature throughout the year. The number of vascular loops and the vascular loop area are increased during the long days of summer, adding communication between the brain and the pituitary at this time. This increase in the vascular connection was associated with an increase in endothelial cell proliferation. In contrast, during the short days of winter a significant reduction in the number of vascular loops and vascular loop area was associated with a decrease in endothelial cell proliferation. Thus, the pituitary microvasculature undergoes 
profound remodelling across the year through a seasonally regulated, VEGF-mediated mechanism.

Seasonal changes in day length are encoded by the duration of melatonin output from the pineal gland during the night, so that the long days of summer are associated with a short duration of melatonin secretion, whereas the short days of winter are linked to a long duration of melatonin production. A major site of action for this photoperiod encoding melatonin signal is the pars tuberalis of the pituitary. This tissue contains the highest density of melatonin receptors in the entire body, and is known to play a crucial role in mediating the melatonin translation of photoperiodic information (57). Melatonin receptors in this region of the pituitary are expressed not only in pars tuberalis specific cells, but also in the vascular loops that will give rise to the long portal vessels (41). The duration of melatonin exposure induces differential expression of VEGF-A isoforms, with proangiogenic VEGF-A $A_{x x x}$ isoforms induced by short duration of the melatonin signal, typical of the long days of summer, and antiangiogenic VEGF- $A_{x x x} b$ isoforms induced by long duration of melatonin signal characteristic of the short days of winter, revealing a mechanism that underlies the seasonal regulation of pituitary microvascular remodelling. This proved to be a conserved mechanism of adaptation, as it was detected in both short and long day seasonal breeders (298) (41).

The pars tuberalis is strategically located at the interphase between the brain and the rest of the pituitary. Activation of melatonin receptors in this region has been known to affect endocrine output from the pars distalis through a paracrine mechanism but, until recently, identification of the effector had not been possible. Indeed, using a hypothalamo-pituitary disconnected animal model, it became apparent that melatonin can potently suppress the production of prolactin secretion within the pars distalis (162); because in that model the pars tuberalis is completely devoid of prolactin-producing lactotroph cells, and the pars distalis does not contain melatonin receptors, a paracrine mode of action was warranted, but characterisation of the signalling factor proved elusive. The melatonin-induced differential expression of VEGF-A isoforms in the pars tuberalis not only underlies seasonal remodelling of the pituitary microvasculature, but also operates as a paracrine signal to regulate the endocrine output of the pars distalis through VEGF receptors present in endocrine and folliculostellate cells within that region (41). In sheep, the stimulation of the anti-angiogenic isoforms VEGF-A $A_{x x x} b$ by the long duration of nocturnal melatonin exposure characteristic of winter potently suppresses prolactin secretion without direct impairment of gonadotrophin output by gonadotroph 
cells, leading to activation of the reproductive axis and enhanced fertility. In contrast, stimulation of the proangiogenic isoforms VEGF-A $A_{x x x}$ by the short duration of nocturnal melatonin exposure characteristic of summer stimulates prolactin secretion and impairs gonadotrophin output, leading to blockade of the reproductive axis and infertility. As prolactin negatively affects the gonadotroph response to hypothalamic stimulation by gonadotropin releasing hormone $(\mathrm{GnRH})$, the melatonin-induced VEGF-mediated regulation of the gonadotrophic axis will also be affected by the VEGF-A regulation of prolactin. In addition to its role during lactation, prolactin has a variety of functions as diverse as central effects to reduce anxiety and peripheral effects to control hair growth and molting. Therefore, the VEGF-A regulation of endocrine output by the pituitary gland can play a major role in seasonal physiology. Because the remaining three endocrine cell types of the pars distalis, i.e. corticotrophs, sommatotrophs and thyrotrophs also posses intimate contacts with FSC and their functions display annual oscillations, it is highly plausible that the seasonal control of the response to stress, growth and metabolism is seemingly mediated by a VEGF-dependent mechanism within the pituitary.

The abundant presence of VEGF-producing FSC in the pituitary infundibular stalk, and the expression of VEGF receptors in these cells, point to another potential role of this protein family in the control of seasonal physiology. Not only are these cells adjacent to the melatonin sensitive pars tuberalis region responsible for annual time measurement, but also in close contact with the median eminence where the hypothalamic neuronal axons terminate and deliver their stimulatory and inhibitory products to be transported by the portal system to the pars distalis. Dynamic structural alterations in another type of glial cells, the ependymal tanycytes, have been shown to facilitate or prevent the delivery of hypothalamic factors in the median eminence through retraction/protraction of 'endfeet' processes that operate at the interphase between the nerve terminals and the fenestrated capillaries (219). This mechanism has been shown to underlie the control of seasonal reproductive cycles in birds (296). Moreover, tanycytic VEGF-A can modulate the plasticity of the blood-brain barrier at the level of the hypothalamus (152). As VEGFA controls fenestration of endothelial cells (226) (76), and also functions as a paracrine factor to relay photoperiodic information to the pars distalis, it is possible that a similar mechanism operates upstream, i.e. in the median eminence, to transfer seasonal cues encoded by the pars tuberalis to the brain. Although this latter alternative requires experimental corroboration, it is clearly apparent that the melatonin-induced differential 
expression of VEGF-A isoforms within the pituitary gland plays an essential role in the physiological adaptation to the seasonal requirements of the species by means of a dual angiogenesis-dependent and paracrine mediated mechanisms.

\section{Neuroprotection}

Of the VEGF family isoforms VEGF-A $A_{165}$ was the first to be identified as a neuroprotective factor and consequently there is a wealth of research concerning the neuroprotective properties of VEGF-A. The seminal publication identification VEGF-A $A_{165}$ to be neuroprotective for adult mouse superior cervical ganglia (SCG) and dorsal root ganglia (DRG) explants, cultured in serum-free conditions (252). Whole DRG explants cultured in the presence of VEGF-A $A_{165}$ had a reduced number of terminal deoxynucleotidyl transferase dUTP nick end labelled (TUNEL)-positive neurons. Further in vitro investigations have revealed VEGF-A $\mathrm{A}_{165}$ and mouse VEGF-A $\mathrm{A}_{164}$ (homologue to human VEGF-A $A_{165}$ ) to be neuroprotective for primary hippocampal neurons against Lglutamic acid-induced excitotoxicity $(25,175)$, hippocampal neuroblastoma cells against serum withdrawal (129) and primary cerebral neuronal cultures against serum and glucose withdrawal (130). The endogenous anti-angiogenic VEGF-A splice variant VEGF-A $A_{165} b$ that only partially activates VEGF receptors(136) is also able to elicit neuroprotection for hippocampal and dorsal root ganglion neurons [114]

Sondell et al. identified a Golgi-like distribution of VEGF-A immunoreactivity in $-30 \%$ of small-diameter neurons in adult mouse dorsal root ganglia, using a VEGF-A polyclonal antibody able to bind all isoforms, suggesting that VEGF-A is synthesized by these neurons (252). VEGFR2 was detected on most neurons (small and large diameter) within the dorsal root ganglia. This suggests VEGF-A $\mathrm{A}_{165}$ and other splice variants are neuroprotective for DRG neurons in an autocrine and paracrine manner in the adult mouse (252). In 2001, Oosthuyse et al. demonstrated a neuroprotective role of VEGF-A in vivo consequently unearthing a potential therapeutic role for VEGF-A in the motor neurodegenerative disease, amyotrophic lateral sclerosis (ALS). Mice with deletion of the hypoxia-response element in the VEGF-A promoter region $\left(V_{E G F}{ }^{\delta / \delta}\right)$ developed adult-onset progressive motor neuron degeneration reminiscent of ALS (210). Furthermore, cross breeding of $\mathrm{VEGF}^{\delta / \delta}$ with SOD1G93A (ALS-associated human superoxide dismutase-1 mutation) mice produced double mutants with more severe 
weakness and reduced survival than the SOD1 ${ }^{\mathrm{G} 93 \mathrm{~A}}$ mutants alone (150). SOD1 ${ }^{\mathrm{G} 93 \mathrm{~A}}$ mice have reduced VEGF-A and VEGFR2 expression levels in the spinal cord suggesting a role in disease pathogenesis (166) and administration of rhVEGF-A $A_{164}$ protein (intraperitoneal (302)) or VEGF-A ${ }_{165}$-expressing lentiviral vector (14) improved motor deficits and survival in SOD1 ${ }^{\mathrm{G} 93 \mathrm{~A}}$ mice. Storkebaum et al. reported that intracerebroventricular delivery of rat VEGF-A ${ }_{164}$ into a rat model of ALS delayed the onset on paralysis, improved motor performance and prolonged survival (257). The group also identified that VEGF-A $\mathrm{A}_{165}$ was transported in an anterograde manner and preserved neuromuscular junctions in these mice (257). In humans, variations in the promoter/leader sequence of the VEGF-A gene have been associated with reduced levels of circulating VEGF-A and this has been reported to increase the risk associated with ALS in some populations (150). On the contrary, further studies have not found an association between VEGF-A haplotypes and ALS potentially undermining a role for VEGF-A in the human $(32,33,60,276)$. Nevertheless the apparent aetiologic role of VEGF-A observed in mouse models of ALS and other types of neurodegeneration highlights the survival role VEGF-A plays in normal health and has provided a firm rationale for researching the therapeutic potential of VEGF-A in neurodegenerative diseases. The ability of transgenically-expressed neuronal VEGF-A $A_{165}$ and exogenous rhVEGF-A $\mathrm{A}_{165}$ to postpone the onset of ALS complies with other reports of VEGFmediated neuroprotection but the mechanism(s) protecting motor neurons in the case of SOD1 ${ }^{\text {G93A }}$ mice remain(s) unresolved. While the autocrine and direct neuroprotective effects of VEGF-A $\mathrm{A}_{165}$ are well documented, it is not known if the in vivo neuroprotection shown to date is achieved exclusively by direct neuronal interactions. In the case of the murine model of ALS, transgenic neuronal overexpression of the VEGF receptor, VEGFR2, also prolongs the survival of SOD1 ${ }^{\mathrm{G} 93 \mathrm{~A}}$ mice (257). Furthermore, VEGF-A 165 prevented axonal degeneration and activation of apoptotic factors, such as caspase-3, in cultured motoneurons transfected to overexpress SOD1 ${ }^{\mathrm{G} 93 \mathrm{~A}}(166)$. These results support the hypothesis that VEGF-induced neuroprotection observed in vivo is mediated primarily by a direct neuronal interaction. Further research has been documented that supports this hypothesis, by disproving a significant effect of VEGF-A $A_{165}$ on angiogenesis, therefore suggesting VEGF- $A_{165}$ protected neurons from ischaemic cell death by a direct action $(260,286)$. Therefore, there is clear evidence that direct application of VEGF-A $\mathrm{A}_{165}$ to neurons is neuroprotective both in vivo and in vitro. 


\section{Ameliorating neurovascular perfusion deficits}

Motoneurons are vulnerable to ischaemia (151) suggesting that chronic neural perfusion deficits may underpin the development of neuronal damage, and in time lead to adultonset neurodegeneration. In the spinal cord of VEGF ${ }^{\delta / \delta}$ mice, VEGF-A levels are reduced by $25 \%$ and angiogenesis is not impaired, as measured by capillary density, yet neural perfusion is deficient causing chronic ischaemia of motoneurons (210). Delivery of plasmid hVEGF-A $A_{165}$ gene transfer preserved neural function in rats with streptozotocininduced diabetes by preventing regression of the vasa nervorum (small arteries that supply peripheral nerves), resulting in restoration of peripheral nerve function (238). These experiments suggest that as well as a direct neuroprotective effect VEGF-A may also promote neurovascular perfusion thereby having an indirect neuroprotective effect.

\section{VEGF-A in PNS neuroprotection and pain}

The involvement of VEGF-A in regulation of other physiological systems has come to the fore primarily due to the entwined roles of the vasculature and other systems, and the emerging role of VEGF-A in the somatosensory system is a good example(223, 264). The somatosensory system, whereby the primary afferent sensory neurons which detect and transmit sensory signals to the central nervous system, is deemed to be highly dependent upon blood supply. In times of peripheral limb ischaemia this sensory nerve is damaged due lack of nutritional supply and consequently sensory perception is altered and pain manifests(265). During times of traumatic nerve injury or stress the sensory nervous system becomes sensitised (117), primarily due to altered expression profiles of voltage gated channels and growth factors(269). Further instances by which pain manifests include diabetic neuropathic pain, chemotherapy induced neuropathic pain and arthtritis. Sensory neurons are dependent upon a vast array of growth factor families e.g. nerve growth factor for development, survival and function. There is now accumulated evidence demonstrating a strong role for VEGF-A dependent actions of the sensory neuron.

VEGF-A was initially associated with sensory neuronal function in the early 2000s ((252) (250)). These studies demonstrated that the expression of VEGF-A and receptors was evident in the sensory neurons of the dorsal root ganglia (DRG) (251) but additionally, VEGF-A had strong neuritogenic actions; driving neuronal survival (251) and regeneration(253). These neuroprotective attributes were only initially used in vivo in the 
mid 2000s $(190,227)$ to prevent in animal models of diabetic neuropathy. These studies used the cytoprotective and regenerative capabilities of VEGF-A as diabetic neuropathy is known to be associated with ischaemia and associated neuronal damage. VEGF-A treatment prevented nerve fibre loss and reduced substance $P$ and calcitonin gene related peptide release(44). Interestingly studies further utilising these neuroprotective actions to initiate recovery following spinal cord injury demonstrated that VEGF-A administration locally to the spinal cord induced regeneration of spinal cord (195), however this neuritogenic action was associated with alterations in nociceptive behaviour. Nesic and colleagues demonstrated that VEGF-A administration to the spinal cord led to a persistent mechanical allodynia (195) In contrast Van Neerven et al. observed that VEGF-A attenuated the development of mechanical allodynia, not to thermal(274). Additional studies following an insult to nervous system, in this case chronic constriction injury to the sciatic nerve that induces neuropathic pain behaviour was associated with increased expression of VEGF-A and VEGFR2 in the dorsal root ganglia sensory neurons and dorsal horn of the spinal cord(163). Isolating DRG sensory neurons, and incubating with VEGF-A, demonstrates a pronounced activation of sensory neurons (163) (170). Interestingly, in support of the pro-nociceptive actions of VEGF-A, administration of anti-VEGF-A (161) or VEGFR inhibitor (vatalanib) (163) resulted in attenuation of neuropathic pain behaviour. This has become widely recognised, with VEGF-A induced pro-nociception mediated by VEGF-A activation of $C$ fibre nociceptors and modulation of non canonical TRP channel activity; TRPV1 $(118,170)$ and TRPA1 (119) activity. Additional work complements this work by identifying VEGF-A signalling induces inflammatory arthritis (98) and cancer pain(242). This would support the concept that anti-VEGF-A or VEGF receptor inhibitory agents would be strong candidates for analgesic development and application in a multitude of disease states.

These studies highlight a strong role for VEGF-A in modulating nociception through a prominent pro-nociceptive action (inducing pain). However in human studies, patients treated with anti-VEGF-A therapy suffer from intensified sensory neuropathy (174). Work by Verheyen et al. investigated the neuroprotective actions further by exploring the rationale that anti-VEGF-A treatment in association with cancer treatment induced pain. Suppression of VEGF-A is a key candidate to treat cancer though many treatments impact upon other systems in leading to off target adverse events. This includes sensory neurons to which suppression of VEGF-A signalling initiates neurodegeneration and pain 
development (281), highlighting that endogenous VEGF-A signalling is necessary for normal sensory neuronal survival and to regulate nociception. This is in contrast to the majority of those publications previously discussed. Further interpretation was required to explore VEGF-A function in nociception.

The c-terminal splice variant of VEGF-A, VEGF-A ${ }_{165} b$ (exon $8 b$ containing), which had been shown to be anti-angiogenic was found to be expressed in the nervous system(20). It is worth noting that all investigations into VEGF-A and nociception until this point had concentrated on the archetypal VEGF-A isoforms (43). Subsequent work identified that VEGF-A $A_{x x x} b$ was cytoprotective, protecting DRG sensory neurons from traumatic (25), chemotherapy $(25,279)$ and hyperglycaemia (119) induced nerve injury, and that these actions were mediated by VEGF receptor $2(25,119)$. Through investigation of this alternative splice variant allowed for VEGF-A mediated neuronal functional to be deciphered. It was discovered that inhibition of VEGF-A signalling in the primary afferent c fibre nociceptor led to development of pain (118) in support of Verheyen and colleagues. However, it was determined that VEGF-A $A_{x x x} b$ isoform was predominantly expressed in normal uninjured nervous tissue $(118,120)$ highlighting that in normal animals inhibition of VEGF-A signalling would be suppressing predominantly VEGF-A $A_{x x x} b$ function. This is of importance as VEGF- $\mathrm{A}_{165} \mathrm{~b}$ administration is antinociceptive, increasing withdrawal threshold in naïve animals (DRG (118) and spinal cord(120)) so suppression of endogenous VEGF-A signalling would be inhibiting an anti-nociceptive signalling pathway thus driving pain. Further investigations elucidated that VEGF-A $A_{x x x}$ isoforms are pronociceptive $(118,120)$ and that VEGF-A $A_{165} b$ treatment attenuated VEGF-A $\mathrm{A}_{165}$ mediated sensitisation of $\mathrm{C}$ fibre nociceptors and consequently pain development (118). Further pathological conditions such as during traumatic nerve injury the expression profiles of these isoforms switch, with the pronociceptive VEGF-A $A_{x x x}$ predominating in DRG sensory neurons with VEGFR2 activated, initiating neuropathic pain development(118). Administration of VEGF-A $A_{x x x} b$ in these rodent models of chronic pain attenuates pain development (118-120).

Understanding VEGF-A mediated nociception has allowed a greater interpretation of the impact that VEGF-A has upon the sensory nervous system. Defining the opposing actions of VEGF-A isoforms provides a powerful opportunity to investigate novel tools to manipulate pain systems. Alternative splicing of VEGF-A family is known to be dependent on key splicing factors to drive preferentially distinct expression profiles, 
for example selecting exon $8 \mathrm{a}$ or exon $8 \mathrm{~b}$ containing isoforms. In terms of pathology e.g. retinopathy(215) and cancer(6), it was identified that SRPK1 drives VEGF-A $A_{x x x}$ preferential expression. Consequently it was determined that SRPK1-SRSF1 signalling was a key regulator of VEGF-A $A_{x x x}$ expression in the sensory nervous system and a key factor in chronic pain development $(118,120)$. Through manipulation of SRPK1 activity through pharmacological inhibition allowed the suppression of VEGF-A $A_{x x x}$ mediated pronociception therefore chronic pain was attenuated $(118,120)$. Investigations into this area has allowed for the expansion of not only how VEGF-A is involved in nociception and chronic pain but has also initiated work into the development of new analgesic regimens that may prove highly beneficial in treating chronic pain.

\section{VEGF in neurogenesis, learning and memory}

Angiogenesis and neurogenesis have long been linked both spatially and mechanistically (165). Neurogenesis was first linked to learning and memory, particularly spatial memory, in the 1990s through observations of experience-dependent hippocampal growth and neurogenesis in birds and mammals (154). Adult mammalian neurogenesis occurs primarily in the subgranular layer of the dentate gyrus and the subventricular zone, from where neurons migrate to the olfactory bulb (63). Neurogenesis has also been found, albeit to a lesser extent and potentially only under non-physiological conditions, in other neocortical regions, the striatum, amygdala and substantia nigra (63).

The contribution of VEGF to central neuronal function, specifically neurogenesis and neuroprotection, and subsequently to hippocampal neurogenesis was also recognised at a relatively early stage (128), largely due to this relationship between neurogenesis and angiogenesis

While there has been considerable debate on the link between neurogenesis and hippocampal learning and memory it is, however, clear that CNS neurogenesis can result from direct effects of VEGF-A on neuronal progenitor cells (128), rather than through an indirect effect on angiogenesis. VEGF-A is secreted by subgranular zone neuronal progenitor cells where it acts to control proliferation (143). Here endogenous VEGF-A affects the proliferative function of neuronal stem/progenitor cells, without influencing the vasculature, and thus can directly control neurogenesis (143).

As long-term potentiation, a well-characterised and studied type of synaptic plasticity that contributes to memory formation, also stimulates hippocampal 
neurogenesis, the hypothesis evolved that VEGF-A could be involved in normal learning and memory. Whether there is a causal link between hippocampal neurogenesis, LTP and learning/memory has, however been debated $(155,160)$. There is strong evidence for effects of VEGF-A on neurogenesis, including its association with exercise(78), environment $(39,66)$, vascular perfusion/angiogenesis $(39)$, direct effects on synaptic function and NMDA receptors (58), and associations between VEGF-A and long term potentiation, and learning and memory (202). There are also indications from clinical (186) and preclinical (214) studies that VEGF receptor blockade may affect learning and memory, and other cognitive functions, but strong causal links have been more difficult to demonstrate. Recent elegant studies in which reversible VEGF-A gain-of-function, and loss-of-function studies were done using inducible transgenic lines have been able to separate effects on the neurogenesis, vascular structure and learning and memory. Loss of VEGF-A had detrimental effects on memory, without notable effects on neurogenesis or vascular density or perfusion. Importantly the positive effect of VEGF-A on memory was evident before any maturation of new neurons, again separating effects on learning and memory from neurogenesis (159).

The evidence for an involvement of VEGF-A in cognitive function, particularly in learning and memory is now compelling. This has important implications for VEGF-A function in normal ageing (110), depression/anxiety (47) and neurodegenerative diseases such as Alzheimer's disease (110)

\section{VEGF and immune function}

\section{Control of endothelial adherence}

A key regulatory component of endothelia-circulatory cell adhesion is the endothelial intraluminal surface layer, the glycocalyx, a dense layer of transmembrane and membrane-bound molecules(49). The glycocalyx is reported to range in thickness from $\sim 200$ to $2000 \mathrm{~nm}$ depending on the tissue bed and this range is significantly larger than the $\sim 10 \mathrm{~nm}$ span of adhesion molecules and receptors $(26,208)$. Consequently a decrease in glycocalyx aids platelet and leukocyte adhesion(49), and one of the many effects of VEGF-A $A_{165}$ on endothelial cells is to decrease the thickness of the glycocalyx(221). Conversely treatment with the VEGF receptor partial agonist VEGF$\mathrm{A}_{165} \mathrm{~b}$ in vivo can rescue disease-associated glycocalyx loss(208). VEGF- $\mathrm{A}_{165}$ treatment of endothelial cells also alters expression of key molecules and receptors involved in 
circulatory cell adhesion and leukocyte transmigration through endothelia. P- and Eselectin endothelial expression is modulated by VEGF-A $(221,261)$. P-selectin glycoprotein ligand-1 (PSGL-1) is the natural ligand of both P- and E-selectin and is expressed by nearly all leukocytes. Von Willebrand Factor (VWF) is another key molecule in the adhesion of leukocytes and platelets to the endothelium and treatment with VEGF-A $A_{165}$ promotes VWF expression(22). While the selectin receptors are strongly associated with the initial capture and rolling stages of leukocyte adhesion, vascular cellular adhesion molecule-1 (VCAM-1) and intercellular adhesion molecule-1 \& (ICAM1) have a greater role in mediating firm adhesion and the initiation of transmigration across the endothelium. VEGF-A also modulates endothelial expression of these key integrin-binding adhesion molecules(80, 182, 233).

VEGF-A causes changes in endothelial permeability through promoting canonical transient receptor potential (TRP) TRPC6-mediated $\mathrm{Ca}^{2+}$ entry and in doing so further contributes to leukocyte transmigration across the endothelium. The rise in intracellular $\mathrm{Ca}^{2+}$ drives phosphorylation changes within the VE-cadherin-catenin complex, triggers actomysoin-mediated contractions that pull on endothelial junctions and activates the lateral border recycling compartment(187, 284). The interaction of leukocytes with cell surface molecules triggers intracellular $\mathrm{Ca}^{2+}$ signals, which can originate from the endoplasmic reticulum or through PECAM-1 (CD31)-mediated TRPC6 channel activity. VEGF-C can promote VCAM-1-mediated adhesion to lymphatic endothelium by inducing endothelial expression of integrin $\alpha 4 \beta 1$ (a.k.a. very late antigen-4, VLA-4) in lymphatic vessels(90). VLA-4 is a natural ligand for VCAM-1, so VEGF-C-can also act as an adhesive ligand that adheres to vascular cell adhesion molecule-1 (VCAM-1)-positive metastatic tumor cells, thereby promoting lymph node metastasis (89). There is also now incrasing evidence that VEGF can regulate the transmigration of $T$ cells from the circulation into areas of antigenic presentation, for instance in tumours. This process has been linked to the expression of chemokine receptors on endothelial cells, and a downregulation of CXCL10 has been implicated in preventing tumour specific $\mathrm{T}$ cells from being able to recognise endothelial cells in tumours. (115) (reviewed in (184))

\section{The monocyte as a VEGF target}

VEGFR1 is expressed in the myeloid progenitor populations (59) and is therefore present on monocytes and appears to be actively involved in pro-migratory signalling 
$(18,140)$. Furthermore maturation and differentiation of monocytes into macrophages increases expression of soluble forms of VEGFR1 (sVEGFR1) $(77,144)$ which appears to demonstrate anti-angiogenic behaviour (144). VEGFR2 has been reported to be expressed by a small subset of Tie-2 expressing monocytes (TAM), although the functional significance of this remains undetermined currently (280). PIGF is also a high affinity ligand for VEGFR1 (211), and blockade of PIGF (through use of a neutralising antibody) is sufficient to prevent monocyte infiltration(13, 82, 100). Consequently there is functional evidence to support a signalling role of VEGFR1, even in the absence of VEGFR2 in most monocyte cell populations. However, VEGF-A independent angiogenesis following anti-VEGF-A treatment has been reported, induced by mobilisation, retention and angiogenic activity of $\mathrm{CD} 11 \mathrm{~b}^{+} \mathrm{Gr} 1^{+}$myeloid cells, via Bv8 expression $(245,246)$. Further experiments demonstrated no role for PIGF and subsequently VEGFR1 in myeloid mediated angiogenic relapse (245). Consequently, although recruited monocytes/macrophages release a host of proangiogenic cytokines (including VEGF), and respond to VEGF, it remains undetermined whether or not targeting VEGF-A will be effective at also blocking monocyte mediated angiogenesis. However, it has become clear that monocyte expression of VEGF is isoform dependent. In patients with metabolic disease (obesity and/or type 2 diabetes), and peripheral arterial disease (PAD) peripheral blood mononuclear cells (PBMCs) demonstrate increased expression of VEGF- $A_{165} b$, VEGF- $A_{189} b$ and VEGF- $A_{121} b(139)$. This is recapitulated in mice treated with high fat high sucrose diets, and in ob/ob obese mice. This has been linked to increased Wnt5a signalling in the monocytes, as monocyte specific Wnt5a gain of function mice also have increased VEGF-A $A_{165} b$ after arterial ischemia(139). The mechanisms through which this Wnt5a dependent monocyte specific splicing switch from pro-angiogenic VEGF- $A_{165}$ to anti-angiogenic VEGF- $A_{165} b$ in ischemic conditions is not known, but once identified could be a potential therapeutic approach for cardiovascular disease.

\section{Conclusion}

Vascular Endothelial Growth Factors, despite their name, act beyond the vasculature, on cells other than endothelial cells and can act in ways other than stimulating growth. While not incorrectly named (they can act as vascular endothelial growth factors) their role in healthy functioning of mammals is widespread and extensive, affecting most tissues even under normal circumstances. This review is not exhaustive of the functions 
of VEGFs - they also act in the ovary, the endometrium, the heart, the renal tubules, and in the gut, to name a few tissues and systems that we have not covered, and they are likely to have many as yet undiscovered functions. Moreover, there are many aspects of the topics covered here that are not covered in as great a depth as we would like. The contribution of VEGFs to disease often drives the research, but an understanding of their role in physiology is also of critical importance, both for understanding what happens in disease, and for understanding how normal physiology works. The complexity of their regulation, the effect of the different genes and their isoforms, and their co-ordination are still not well understood, but it is now increasingly clear that they play a key role in homeostasis, particularly in fluid homeostasis in the vasculature, across multiple organs, and sensory and somatosensory systems in the nervous system, as well as in remodeling situations such as during wound healing and response to injury. Although there has been extensive work carried out over the years on the involvement of VEGFS in pathology, perhaps the coming decade will yield significant insights into the role of these complex and fascinating proteins in controlling normal function in mammals, including humans.

\section{Acknowledgements}

This work was put together by members of the Microvascular Research Laboratories at the University of Bristol, who worked there between 2000 when it was founded and 2013 when the Laboratory was closed. We would like to thank all 84 members of the laboratories who worked there during that time, as well as the various funders including the British Heart Foundation, The Medical Research Council, the Wellcome Trust, Diabetes UK, the Richard Bright VEGF Research Trust and many other supporters. 
Figure Legends

Figure 1. Schematic of the VEGF receptors. VEGFR1 and VEGFR2 both have seven IgG domains, and when they bind VEGF act as homodimers. The intracellular domain contains a kinase insert domain, and the receptors can heterodimerise. VEGFR3 is a similar receptor but is proteolytically cleaved during synthesis, and held together with a disulphine bond between IgG 4 and 5. The co-receptors NP1 and NP2 interact with the VEGF receptors to aid signalling, intracellular sorting and recycling to the membrane. VEGF-B and PIGF both bind only to VEGFR1, VEGF-A binds both VEGFR1 and VEGFR2 and VEGF-C and VEGF-D bind to VEGFR3, but when proteolytically processed increase their affinity for VEGFR2.

Figure 2. Splicing of the VEGF-A gene. The 8 exons are differentially spliced to form multiple isoforms in two primary families, the pro-angiogenic VEGF-A $A_{x x x}$, which use the proximal splice site in exon 8 , and the partial agonist VEGF-A $A_{x x x} b$ family, which can prevent VEGF-A $A_{x x x}$ mediated angiogenesis, but can signal to prevent cytotoxicity through partial activation of VEGFR2.

Figure 3. Coverage of endothelial fenestrations by glycocalyx. Induction of fenestrations has been shown by VEGF, and VEGF knockdown in the glomerulus reduces fenestrations in glomerular endothelial cells. The endothelial cells, including the fenestrations, are covered with a glycocalyx (imaged in A using electron tomography transmission electron microscopy) (9). B. In diabetes the glycocalyx is lost, but can be restored by treatment with VEGF-A ${ }_{165} b(208)$.

\section{References}

1. Ablonczy Z, Prakasam A, Fant J, Fauq A, Crosson C, and Sambamurti K. Pigment epithelium-derived factor maintains retinal pigment epithelium function by inhibiting vascular endothelial growth factor-R2 signaling through gamma-secretase. J Biol Chem 284: 3017730186, 2009.

2. Aiello LP, Avery RL, Arrigg PG, Keyt BA, Jampel HD, Shah ST, Pasquale LR, Thieme H, Iwamoto MA, Park JE, Nguyen HV, Aiello LM, Ferrara N, and King GL. Vascular endothelial growth factor in ocular fluid of patients with diabetic retinopathy and other retinal disorders. New England Journal of Medicine 331: 1480-1487, 1994.

3. Akkoyun I, Karabay G, Haberal N, Dagdeviren A, Yilmaz G, Oto S, Erkanli L, and Akova YA. Structural consequences after intravitreal bevacizumab injection without increasing apoptotic cell death in a retinopathy of prematurity mouse model. Acta Ophthalmol, 2010.

4. Alavi A, Hood JD, Frausto R, Stupack DG, and Cheresh DA. Role of Raf in vascular protection from distinct apoptotic stimuli. Science 301: 94-96, 2003. 
5. Alon T, Hemo I, Itin A, Pe'er J, Stone J, and Keshet E. Vascular endothelial growth factor acts as a survival factor for newly formed retinal vessels and has implications for retinopathy of prematurity. Nat Med 1: 1024-1028, 1995.

6. Amin EM, Oltean S, Hua J, Gammons MV, Hamdollah-Zadeh M, Welsh GI, Cheung MK, Ni L, Kase S, Rennel ES, Symonds KE, Nowak DG, Royer-Pokora B, Saleem MA, Hagiwara M, Schumacher VA, Harper SJ, Hinton DR, Bates DO, and Ladomery MR. WT1 mutants reveal SRPK1 to be a downstream angiogenesis target by altering VEGF splicing. Cancer Cell 20: 768-780, 2011.

7. Arany Z, Foo SY, Ma Y, Ruas JL, Bommi-Reddy A, Girnun G, Cooper M, Laznik D, Chinsomboon J, Rangwala SM, Baek KH, Rosenzweig A, and Spiegelman BM. HIFindependent regulation of VEGF and angiogenesis by the transcriptional coactivator PGC-1alpha. Nature 451: 1008-1012, 2008.

8. Arcondeguy $\mathbf{T}$, Lacazette E, Millevoi $\mathbf{S}$, Prats $\mathbf{H}$, and Touriol C. VEGF-A mRNA processing, stability and translation: a paradigm for intricate regulation of gene expression at the post-transcriptional level. Nucleic Acids Res 41: 7997-8010, 2013.

9. Arkill KP, Qvortrup K, Starborg T, Mantell JM, Knupp C, Michel CC, Harper SJ, Salmon AH, Squire JM, Bates DO, and Neal CR. Resolution of the three dimensional structure of components of the glomerular filtration barrier. BMC nephrology 15: 24, 2014.

10. Asanuma $\mathbf{K}$ and Mundel $\mathbf{P}$. The role of podocytes in glomerular pathobiology. Clin Exp Nephrol 7: 255-259, 2003.

11. Atkins GB and Jain MK. Role of Kruppel-like transcription factors in endothelial biology. Circ Res 100: 1686-1695, 2007.

12. Avci B, Avci R, Inan UU, and Kaderli B. Comparative evaluation of apoptotic activity in photoreceptor cells after intravitreal injection of bevacizumab and pegaptanib sodium in rabbits. Invest Ophthalmol Vis Sci 50: 3438-3446, 2009.

13. Avraham-Davidi I, Yona S, Grunewald M, Landsman L, Cochain C, Silvestre JS, Mizrahi H, Faroja M, Strauss-Ayali D, Mack M, Jung S, Keshet E, Grunewald M, Avraham I, Dor Y, Bachar-Lustig E, Itin A, Jung S, Chimenti S, Landsman L, Abramovitch R, and Keshet E. On-site education of VEGF-recruited monocytes improves their performance as angiogenic and arteriogenic accessory cells

VEGF-induced adult neovascularization: recruitment, retention, and role of accessory cells. The Journal of experimental medicine 210: 2611-2625, 2013.

14. Azzouz M, Ralph GS, Storkebaum E, Walmsley LE, Mitrophanous KA, Kingsman SM, Carmeliet $\mathbf{P}$, and Mazarakis ND. VEGF delivery with retrogradely transported lentivector prolongs survival in a mouse ALS model. Nature 429: 413-417, 2004.

15. Bailey E, Harper SJ, Pringle JH, Baker F, Furness PN, Salant DJ, and Feehally J. Visceral glomerular epithelial cell DNA synthesis in experimental and human membranous disease. Exp Nephrol 6: 352-358., 1998.

16. Ballermann BJ. Glomerular endothelial cell differentiation. Kidney Int 67: 1668-1671, 2005.

17. Ballmer-Hofer K, Andersson AE, Ratcliffe LE, and Berger P. Neuropilin-1 promotes VEGFR-2 trafficking through Rab11 vesicles thereby specifying signal output. Blood, 2011.

18. Barleon B, Sozzani S, Zhou D, Weich HA, Mantovani A, and Marme D. Migration of human monocytes in response to vascular endothelial growth factor (VEGF) is mediated via the VEGF receptor flt-1. Blood 87: 3336-3343, 1996.

19. Barratt SL, Blythe T, Jarrett C, Ourradi K, Shelley-Fraser G, Day MJ, Qiu Y, Harper S, Maher TM, Oltean S, Hames T, Scotton C, Welsh GI, Bates DO, and Millar AB. Differential expression of VEGF-Axxx isoforms is critical for development of Pulmonary Fibrosis. Am J Respir Crit Care Med in press, 2017.

20. Bates D, Cui T, Doughty J, Winkler M, Sugiono M, Shields J, Peat D, Gillatt D, and Harper S. VEGF165b, an inhibitory splice variant of vascular endothelial growth factor, is downregulated in renal cell carcinoma. Cancer research 62: 4123-4131, 2002.

21. Bates DO, Cui TG, Doughty JM, Winkler M, Sugiono M, Shields JD, Peat D, Gillatt D, and Harper SJ. VEGF165b, an inhibitory splice variant of vascular endothelial growth factor, is down-regulated in renal cell carcinoma. Cancer Res 62: 4123-4131., 2002. 
22. Bauer AT, Suckau J, Frank K, Desch A, Goertz L, Wagner AH, Hecker M, Goerge T, Umansky L, Beckhove P, Utikal J, Gorzelanny C, Diaz-Valdes N, Umansky V, and Schneider SW. von Willebrand factor fibers promote cancer-associated platelet aggregation in malignant melanoma of mice and humans. Blood 125: 3153-3163, 2015.

23. Baum O, Da Silva-Azevedo L, Willerding G, Wockel A, Planitzer G, Gossrau R, Pries AR, and Zakrzewicz A. Endothelial NOS is main mediator for shear stress-dependent angiogenesis in skeletal muscle after prazosin administration. Am J Physiol Heart Circ Physiol 287: $\mathrm{H} 2300-2308,2004$.

24. Baumwell S and Karumanchi SA. Pre-eclampsia: clinical manifestations and molecular mechanisms. Nephron Clin Pract 106: c72-81, 2007.

25. Beazley-Long N, Hua J, Jehle T, Hulse RP, Dersch R, Lehrling C, Bevan H, Qiu Y, Lagreze WA, Wynick D, Churchill AJ, Kehoe P, Harper SJ, Bates DO, and Donaldson LF. VEGF-A165b Is an Endogenous Neuroprotective Splice Isoform of Vascular Endothelial Growth Factor A in Vivo and in Vitro. Am J Pathol 183: 918-929, 2013.

26. Becker BF, Chappell D, Bruegger D, Annecke T, and Jacob M. Therapeutic strategies targeting the endothelial glycocalyx: acute deficits, but great potential. Cardiovasc Res 87: 300310, 2010.

27. Berse B, Brown LF, Van de Water L, Dvorak HF, and Senger DR. Vascular permeability factor (vascular endothelial growth factor) gene is expressed differentially in normal tissues, macrophages, and tumors. Mol Biol Cell 3: 211-220, 1992.

28. Bevan HS, van den Akker NM, Qiu Y, Polman JA, Foster RR, Yem J, Nishikawa A, Satchell SC, Harper SJ, Gittenberger-de Groot AC, and Bates DO. The Alternatively Spliced Anti-Angiogenic Family of VEGF Isoforms VEGF(xxx)b in Human Kidney Development. Nephron Physiol 110: p57-p67, 2008.

29. Bhandari V, Choo-Wing R, Chapoval SP, Lee CG, Tang C, Kim YK, Ma B, Baluk P, Lin MI, McDonald DM, Homer RJ, Sessa WC, and Elias JA. Essential role of nitric oxide in VEGF-induced, asthma-like angiogenic, inflammatory, mucus, and physiologic responses in the lung. Proc Natl Acad Sci U S A 103: 11021-11026, 2006.

30. Bonner JS, Lantier L, Hasenour CM, James FD, Bracy DP, and Wasserman DH. Muscle-specific vascular endothelial growth factor deletion induces muscle capillary rarefaction creating muscle insulin resistance. Diabetes 62: 572-580, 2013.

31. Breier G, Albrecht U, Sterrer S, and Risau W. Expression of vascular endothelial growth factor during embryonic angiogenesis and endothelial cell differentiation. Development 114: 521-532, 1992.

32. Brockington A, Wharton SB, Fernando M, Gelsthorpe $\mathrm{CH}$, Baxter L, Ince PG, Lewis CE, and Shaw PJ. Expression of vascular endothelial growth factor and its receptors in the central nervous system in amyotrophic lateral sclerosis. Journal of neuropathology and experimental neurology 65: 26-36, 2006.

33. Brockington A, Wokke B, Nixon H, Hartley J, and Shaw PJ. Screening of the transcriptional regulatory regions of vascular endothelial growth factor receptor 2 (VEGFR2) in amyotrophic lateral sclerosis. BMC medical genetics 8: 23, 2007.

34. Brown KR, England KM, Goss KL, Snyder JM, and Acarregui MJ. VEGF induces airway epithelial cell proliferation in human fetal lung in vitro. Am J Physiol Lung Cell Mol Physiol 281: L1001-1010, 2001.

35. Brown LF, Berse B, Jackman RW, Tognazzi K, Manseau EJ, Senger DR, and Dvorak HF. Expression of vascular permeability factor (vascular endothelial growth factor) and its receptors in adenocarcinomas of the gastrointestinal tract. Cancer Res 53: 4727-4735, 1993.

36. Brown LF, Berse B, Tognazzi K, Manseau EJ, Van de Water L, Senger DR, Dvorak HF, and Rosen S. Vascular permeability factor mRNA and protein expression in human kidney. Kidney Int 42: 1457-1461, 1992.

37. Cai J, Ahmad S, Jiang WG, Huang J, Kontos CD, Boulton M, and Ahmed A. Activation of vascular endothelial growth factor receptor-1 sustains angiogenesis and Bcl-2 expression via the phosphatidylinositol 3-kinase pathway in endothelial cells. Diabetes 52: 29592968, 2003.

38. Cai WJ, Kocsis E, Luo X, Schaper W, and Schaper J. Expression of endothelial nitric oxide synthase in the vascular wall during arteriogenesis. Mol Cell Biochem 264: 193-200, 2004. 
39. Cao L, Jiao X, Zuzga DS, Liu Y, Fong DM, Young D, and During MJ. VEGF links hippocampal activity with neurogenesis, learning and memory. Nat Genet 36: 827-835, 2004.

40. Cao R, Eriksson A, Kubo H, Alitalo K, Cao Y, and Thyberg J. Comparative evaluation of FGF-2-, VEGF-A-, and VEGF-C-induced angiogenesis, lymphangiogenesis, vascular fenestrations, and permeability. Circ Res 94: 664-670, 2004.

41. Castle-Miller J, Bates DO, and Tortonese DJ. Mechanisms regulating angiogenesis underlie seasonal control of pituitary function. Proc Natl Acad Sci U S A 114: E2514-E2523, 2017.

42. Cebe Suarez S, Pieren M, Cariolato L, Arn S, Hoffmann U, Bogucki A, Manlius C, Wood J, and Ballmer-Hofer K. A VEGF-A splice variant defective for heparan sulfate and neuropilin-1 binding shows attenuated signaling through VEGFR-2. Cell Mol Life Sci 63: 20672077, 2006.

43. Cébe Suarez S PM, Cariolato L, Arn S, Hoffmann U, Bogucki A, Manlius C, Wood J, Ballmer-Hofer K. A VEGF-A splice variant defective for heparan sulfate and neuropilin-1 binding shows attenuated signaling through VEGFR-2. Cell Mol Life Sci 63: 2067-2077, 2006.

44. Chattopadhyay M, Krisky D, Wolfe D, Glorioso JC, Mata M, and Fink DJ. HSVmediated gene transfer of vascular endothelial growth factor to dorsal root ganglia prevents diabetic neuropathy. Gene Ther 12: 1377-1384, 2005.

45. Chen HX and Cleck JN. Adverse effects of anticancer agents that target the VEGF pathway. Nat Rev Clin Oncol 6: 465-477, 2009.

46. Christian HC, Imirtziadis L, and Tortonese D. Ultrastructural changes in lactotrophs and folliculo-stellate cells in the ovine pituitary during the annual reproductive cycle. $J$ Neuroendocrinol 27: 277-284, 2015.

47. Clark-Raymond A and Halaris A. VEGF and depression: a comprehensive assessment of clinical data. Journal of psychiatric research 47: 1080-1087, 2013.

48. Compernolle V, Brusselmans K, Acker T, Hoet P, Tjwa M, Beck H, Plaisance S, Dor Y, Keshet E, Lupu F, Nemery B, Dewerchin M, Van Veldhoven P, Plate K, Moons L, Collen D, and Carmeliet P. Loss of HIF-2alpha and inhibition of VEGF impair fetal lung maturation, whereas treatment with VEGF prevents fatal respiratory distress in premature mice. Nat Med 8: 702-710, 2002.

49. Constantinescu AA, Vink $\mathbf{H}$, and Spaan JA. Endothelial cell glycocalyx modulates immobilization of leukocytes at the endothelial surface. Arterioscler Thromb Vasc Biol 23: 15411547, 2003.

50. Cosgrove GP, Brown KK, Schiemann WP, Serls AE, Parr JE, Geraci MW, Schwarz MI, Cool CD, and Worthen GS. Pigment epithelium-derived factor in idiopathic pulmonary fibrosis: a role in aberrant angiogenesis. Am J Respir Crit Care Med 170: 242-251, 2004.

51. Cui TG, Foster RR, Saleem MA, Mathieson PW, Gillatt DA, Bates DO, and Harper SJ. Differentiated human podocytes endogenously express an inhibitory isoform of vascular endothelial growth factor (VEGF165b) mRNA and protein. Am J Physiol Renal Physiol 25: 25, 2003.

52. Dane MJ, van den Berg BM, Avramut MC, Faas FG, van der Vlag J, Rops AL, Ravelli RB, Koster BJ, van Zonneveld AJ, Vink H, and Rabelink TJ. Glomerular endothelial surface layer acts as a barrier against albumin filtration. Am J Pathol 182: 1532-1540, 2013.

53. Daniel PM and Prichard MM. The vascular arrangements of the pituitary gland. $Q \mathrm{~J}$ Exp Physiol Cogn Med Sci 42: 237-248, 1957.

54. De Bock K, Georgiadou M, and Carmeliet P. Role of endothelial cell metabolism in vessel sprouting. Cell metabolism 18: 634-647, 2013.

55. De Bock K, Georgiadou M, Schoors S, Kuchnio A, Wong BW, Cantelmo AR, Quaegebeur A, Ghesquiere B, Cauwenberghs S, Eelen G, Phng LK, Betz I, Tembuyser B, Brepoels K, Welti J, Geudens I, Segura I, Cruys B, Bifari F, Decimo I, Blanco R, Wyns S, Vangindertael J, Rocha S, Collins RT, Munck S, Daelemans D, Imamura H, Devlieger R, Rider M, Van Veldhoven PP, Schuit F, Bartrons R, Hofkens J, Fraisl P, Telang S, Deberardinis RJ, Schoonjans L, Vinckier S, Chesney J, Gerhardt H, Dewerchin M, and Carmeliet P. Role of PFKFB3-driven glycolysis in vessel sprouting. Cell 154: 651-663, 2013.

56. De Paepe ME, Greco D, and Mao Q. Angiogenesis-related gene expression profiling in ventilated preterm human lungs. Exp Lung Res 36: 399-410, 2010. 
57. de Reviers MM, Ravault JP, Tillet Y, and Pelletier J. Melatonin binding sites in the sheep pars tuberalis. Neurosci Lett 100: 89-93, 1989.

58. De Rossi P, Harde E, Dupuis JP, Martin L, Chounlamountri N, Bardin M, Watrin C, Benetollo C, Pernet-Gallay K, Luhmann HJ, Honnorat J, Malleret G, Groc L, Acker-Palmer A, Salin PA, and Meissirel C. A critical role for VEGF and VEGFR2 in NMDA receptor synaptic function and fear-related behavior. Molecular psychiatry 21: 1768-1780, 2016.

59. de Vries C, Escobedo JA, Ueno H, Houck K, Ferrara N, and Williams LT. The fms-like tyrosine kinase, a receptor for vascular endothelial growth factor. Science 255: 989-991, 1992.

60. Del Bo R, Scarlato M, Ghezzi S, Martinelli-Boneschi F, Corti S, Locatelli F, Santoro D, Prelle A, Briani C, Nardini M, Siciliano G, Mancuso M, Murri L, Bresolin N, and Comi GP. Absence of angiogenic genes modification in Italian ALS patients. Neurobiology of aging 29: 314316, 2008.

61. dela Paz NG, Walshe TE, Leach LL, Saint-Geniez M, and D'Amore PA. Role of shearstress-induced VEGF expression in endothelial cell survival. J Cell Sci 125: 831-843, 2012.

62. Doddaballapur A, Michalik KM, Manavski Y, Lucas T, Houtkooper RH, You X, Chen W, Zeiher AM, Potente M, Dimmeler S, and Boon RA. Laminar shear stress inhibits endothelial cell metabolism via KLF2-mediated repression of PFKFB3. Arteriosclerosis, thrombosis, and vascular biology 35: 137-145, 2015.

63. Dokter $\mathbf{M}$ and von Bohlen und Halbach $\mathrm{O}$. Neurogenesis within the adult hippocampus under physiological conditions and in depression. Neural regeneration research 7: 552-559, 2012. 64. Domigan CK, Warren CM, Antanesian V, Happel K, Ziyad S, Lee S, Krall A, Duan L, Torres-Collado AX, Castellani LW, Elashoff D, Christofk HR, van der Bliek AM, Potente M, and Iruela-Arispe ML. Autocrine VEGF maintains endothelial survival through regulation of metabolism and autophagy. Journal of cell science 128: 2236-2248, 2015.

65. Drumond MC and Deen WM. Structural determinants of glomerular hydraulic permeability. Am J Physiol 266: F1-12, 1994.

66. During MJ and Cao L. VEGF, a mediator of the effect of experience on hippocampal neurogenesis. Current Alzheimer research 3: 29-33, 2006.

67. Dvorak HF, Brown LF, Detmar M, and Dvorak AM. Vascular permeability factor/vascular endothelial growth factor, microvascular hyperpermeability, and angiogenesis. Am J Pathol 146: 1029-1039, 1995.

68. Ebina M, Shimizukawa M, Shibata N, Kimura Y, Suzuki T, Endo M, Sasano H, Kondo T, and Nukiwa T. Heterogeneous increase in CD34-positive alveolar capillaries in idiopathic pulmonary fibrosis. Am J Respir Crit Care Med 169: 1203-1208, 2004.

69. Eelen G, de Zeeuw P, Simons $\mathbf{M}$, and Carmeliet $\mathbf{P}$. Endothelial cell metabolism in normal and diseased vasculature. Circulation research 116: 1231-1244, 2015.

70. Egginton S and Hudlicka $\mathbf{O}$. Early changes in performance, blood flow and capillary fine structure in rat fast muscles induced by electrical stimulation. J Physiol (Lond) 515 ( Pt 1): 265275, 1999.

71. Elias I, Franckhauser S, Ferre T, Vila L, Tafuro S, Munoz S, Roca C, Ramos D, Pujol A, Riu E, Ruberte J, and Bosch F. Adipose tissue overexpression of vascular endothelial growth factor protects against diet-induced obesity and insulin resistance. Diabetes 61: 1801-1813, 2012. 72. Elmasri H, Karaaslan C, Teper Y, Ghelfi E, Weng M, Ince TA, Kozakewich H, Bischoff $\mathbf{J}$, and Cataltepe S. Fatty acid binding protein 4 is a target of VEGF and a regulator of cell proliferation in endothelial cells. Faseb J 23: 3865-3873, 2009.

73. Eremina V, Jefferson JA, Kowalewska J, Hochster H, Haas M, Weisstuch J, Richardson C, Kopp JB, Kabir MG, Backx PH, Gerber HP, Ferrara N, Barisoni L, Alpers CE, and Quaggin SE. VEGF inhibition and renal thrombotic microangiopathy. N Engl J Med 358: 1129-1136, 2008.

74. Eremina V and Quaggin SE. The role of VEGF-A in glomerular development and function. Curr Opin Nephrol Hypertens 13: 9-15, 2004.

75. Eremina V, Sood M, Haigh J, Nagy A, Lajoie G, Ferrara N, Gerber HP, Kikkawa Y, Miner JH, and Quaggin SE. Glomerular-specific alterations of VEGF-A expression lead to distinct congenital and acquired renal diseases. J Clin Invest 111: 707-716, 2003. 
76. Esser S, Wolburg K, Wolburg H, Breier G, Kurzchalia T, and Risau W. Vascular Endothelial Growth Factor Induces Endothelial Fenestrations In Vitro. Journal of Cell Biology 140: 947-959, 1998.

77. Eubank TD, Roberts R, Galloway M, Wang Y, Cohn DE, and Marsh CB. GM-CSF induces expression of soluble VEGF receptor-1 from human monocytes and inhibits angiogenesis in mice. Immunity 21: 831-842, 2004.

78. Fabel K, Fabel K, Tam B, Kaufer D, Baiker A, Simmons N, Kuo CJ, and Palmer TD. VEGF is necessary for exercise-induced adult hippocampal neurogenesis. Eur J Neurosci 18: 2803-2812, 2003.

79. Fava RA, Olsen NJ, Spencer-Green G, Yeo KT, Yeo TK, Berse B, Jackman RW, Senger DR, Dvorak HF, and Brown LF. Vascular permeability factor/endothelial growth factor (VPF/VEGF): accumulation and expression in human synovial fluids and rheumatoid synovial tissue. J Exp Med 180: 341-346, 1994.

80. Fearnley GW, Odell AF, Latham AM, Mughal NA, Bruns AF, Burgoyne NJ, HomerVanniasinkam S, Zachary IC, Hollstein MC, Wheatcroft SB, and Ponnambalam S. VEGF-A isoforms differentially regulate ATF-2-dependent VCAM-1 gene expression and endothelialleukocyte interactions. Mol Biol Cell 25: 2509-2521, 2014.

81. Fehrenbach $\mathbf{H}$, Kasper $M$, Haase $M$, Schuh $D$, and Muller $M$. Differential immunolocalization of VEGF in rat and human adult lung, and in experimental rat lung fibrosis: light, fluorescence, and electron microscopy. Anat Rec 254: 61-73, 1999.

82. Fischer C, Jonckx B, Mazzone $M$, Zacchigna S, Loges S, Pattarini L, Chorianopoulos E, Liesenborghs L, Koch M, De Mol M, Autiero M, Wyns S, Plaisance S, Moons L, van Rooijen N, Giacca M, Stassen JM, Dewerchin M, Collen D, and Carmeliet P. Anti-PIGF inhibits growth of VEGF(R)-inhibitor-resistant tumors without affecting healthy vessels. Cell 131: 463-475, 2007.

83. Foster RR, Armstrong L, Baker S, Wong DW, Wylie EC, Ramnath R, Jenkins R, Singh A, Steadman R, Welsh GI, Mathieson PW, and Satchell SC. Glycosaminoglycan regulation by VEGFA and VEGFC of the glomerular microvascular endothelial cell glycocalyx in vitro. Am J Pathol 183: 604-616, 2013.

84. Foster RR, Hole R, Anderson K, Satchell SC, Coward RJ, Mathieson PW, Gillatt DA, Saleem MA, Bates DO, and Harper SJ. Functional evidence that vascular endothelial growth factor may act as an autocrine factor on human podocytes. Am J Physiol Renal Physiol 284: F1263-1273, 2003.

85. Foster RR, Saleem MA, Mathieson PW, Bates DO, and Harper SJ. Vascular endothelial growth factor and nephrin interact and reduce apoptosis in human podocytes. $A m \mathrm{~J}$ Physiol Renal Physiol 31: 31, 2004.

86. Foster RR, Slater SC, Seckley J, Kerjaschki D, Bates DO, Mathieson PW, and Satchell SC. Vascular endothelial growth factor-C, a potential paracrine regulator of glomerular permeability, increases glomerular endothelial cell monolayer integrity and intracellular calcium. Am J Pathol 173: 938-948, 2008.

87. Fufaa GD, Weil EJ, Lemley KV, Knowler WC, Brosius FC, 3rd, Yee B, Mauer M, and Nelson RG. Structural Predictors of Loss of Renal Function in American Indians with Type 2 Diabetes. Clin J Am Soc Nephrol 11: 254-261, 2016.

88. Furuhashi $\mathbf{M}$ and Hotamisligil GS. Fatty acid-binding proteins: role in metabolic diseases and potential as drug targets. Nature reviews Drug discovery 7: 489-503, 2008.

89. Garmy-Susini B, Avraamides CJ, Desgrosellier JS, Schmid MC, Foubert P, Ellies LG, Lowy AM, Blair SL, Vandenberg SR, Datnow B, Wang HY, Cheresh DA, and Varner J. PI3Kalpha activates integrin alpha4beta1 to establish a metastatic niche in lymph nodes. Proc Natl Acad Sci U S A 110: 9042-9047, 2013.

90. Garmy-Susini B, Avraamides CJ, Schmid MC, Foubert P, Ellies LG, Barnes L, Feral C, Papayannopoulou T, Lowy A, Blair SL, Cheresh D, Ginsberg M, and Varner JA. Integrin alpha4beta1 signaling is required for lymphangiogenesis and tumor metastasis. Cancer Res 70 : 3042-3051, 2010.

91. Gerber HP, Dixit V, and Ferrara N. Vascular endothelial growth factor induces expression of the antiapoptotic proteins $\mathrm{Bcl}-2$ and $\mathrm{A} 1$ in vascular endothelial cells. $\mathrm{J}$ Biol Chem 273: 13313-13316, 1998. 
92. Gerber HP, Hillan KJ, Ryan AM, Kowalski J, Keller GA, Rangell L, Wright BD, Radtke F, Aguet M, and Ferrara N. VEGF is required for growth and survival in neonatal mice. Development 126: 1149-1159, 1999.

93. Gerber HP, McMurtrey A, Kowalski J, Yan M, Keyt BA, Dixit V, and Ferrara N. Vascular endothelial growth factor regulates endothelial cell survival through the phosphatidylinositol 3'-kinase/Akt signal transduction pathway. Requirement for Flk-1/KDR activation. J Biol Chem 273: 30336-30343, 1998.

94. Goettsch W, Gryczka C, Korff T, Ernst E, Goettsch C, Seebach J, Schnittler HJ, Augustin HG, and Morawietz H. Flow-dependent regulation of angiopoietin-2. J Cell Physiol 214: 491-503, 2008.

95. Green JD. The comparative anatomy of the hypophysis, with special reference to its blood supply and innervation. Am J Anat 88: 225-311, 1951.

96. Green JD and Harris GW. The neurovascular link between the neurohypophysis and adenohypophysis. J Endocrinol 5: 136-146, 1947.

97. Greenberg JM, Thompson FY, Brooks SK, Shannon JM, McCormick-Shannon K, Cameron JE, Mallory BP, and Akeson AL. Mesenchymal expression of vascular endothelial growth factors D and A defines vascular patterning in developing lung. Dev Dyn 224: 144-153, 2002.

98. Grosios K, Wood J, Esser R, Raychaudhuri A, and Dawson J. Angiogenesis inhibition by the novel VEGF receptor tyrosine kinase inhibitor, PTK787/ZK222584, causes significant antiarthritic effects in models of rheumatoid arthritis. Inflamm Res 53: 133-142, 2004.

99. Grunewald FS, Prota AE, Giese A, and Ballmer-Hofer K. Structure-function analysis of VEGF receptor activation and the role of coreceptors in angiogenic signaling. Biochim Biophys Acta 1804: 567-580, 2010.

100. Grunewald M, Avraham I, Dor Y, Bachar-Lustig E, Itin A, Jung S, Chimenti S, Landsman L, Abramovitch R, and Keshet E. VEGF-induced adult neovascularization: recruitment, retention, and role of accessory cells. Cell 124: 175-189, 2006.

101. Hagberg C, Mehlem A, Falkevall A, Muhl L, and Eriksson U. Endothelial fatty acid transport: role of vascular endothelial growth factor B. Physiology 28: 125-134, 2013.

102. Hagberg CE, Falkevall A, Wang X, Larsson E, Huusko J, Nilsson I, van Meeteren LA, Samen E, Lu L, Vanwildemeersch M, Klar J, Genove G, Pietras K, Stone-Elander S, Claesson-Welsh L, Yla-Herttuala S, Lindahl P, and Eriksson U. Vascular endothelial growth factor B controls endothelial fatty acid uptake. Nature 464: 917-921, 2010.

103. Hagberg CE, Mehlem A, Falkevall A, Muhl L, Fam BC, Ortsater H, Scotney P, Nyqvist D, Samen E, Lu L, Stone-Elander S, Proietto J, Andrikopoulos S, Sjoholm A, Nash A, and Eriksson U. Targeting VEGF-B as a novel treatment for insulin resistance and type 2 diabetes. Nature 490: 426-430, 2012.

104. Harper SJ and Bates DO. VEGF-A splicing: the key to anti-angiogenic therapeutics? Nat Rev Cancer 8: 880-887, 2008.

105. Heiduschka P, Julien S, Hofmeister S, Bartz-Schmidt KU, and Schraermeyer U. Bevacizumab (avastin) does not harm retinal function after intravitreal injection as shown by electroretinography in adult mice. Retina 28: 46-55, 2008.

106. Hillman NJ, Whittles CE, Pocock TM, Williams B, and Bates DO. Differential effects of vascular endothelial growth factor-C and placental growth factor-1 on the hydraulic conductivity of frog mesenteric capillaries. J Vasc Res 38: 176-186, 2001.

107. Hirschhaeuser F, Sattler UG, and Mueller-Klieser W. Lactate: a metabolic key player in cancer. Cancer research 71: 6921-6925, 2011.

108. Hjalmarsson C, Johansson BR, and Haraldsson B. Electron microscopic evaluation of the endothelial surface layer of glomerular capillaries. Microvasc Res 67: 9-17, 2004.

109. Hohenstein B, Colin M, Foellmer C, Amann KU, Brekken RA, Daniel C, and Hugo CP. Autocrine VEGF-VEGF-R loop on podocytes during glomerulonephritis in humans. Nephrol Dial Transplant 25: 3170-3180, 2010.

110. Hohman TJ, Bell SP, Jefferson AL, and Alzheimer's Disease Neuroimaging I. The role of vascular endothelial growth factor in neurodegeneration and cognitive decline: exploring interactions with biomarkers of Alzheimer disease. JAMA neurology 72: 520-529, 2015. 
111. Hoier B, Prats C, Qvortrup K, Pilegaard H, Bangsbo J, and Hellsten Y. Subcellular localization and mechanism of secretion of vascular endothelial growth factor in human skeletal muscle. Faseb J 27: 3496-3504, 2013.

112. Houck KA, Leung DW, Rowland AM, Winer J, and Ferrara N. Dual regulation of vascular endothelial growth factor bioavailability by genetic and proteolytic mechanisms. $\mathrm{J}$ Biol Chem 267: 26031-26037, 1992.

113. Houssay BA, Biasotti A, and Sammartino R. CR Soc Biol, Paris, 120, : 725, 1935.

114. Hua J, Spee C, Kase S, Rennel ES, Magnussen AL, Qiu Y, Varey A, Dhayade S, Churchill AJ, Harper SJ, Bates DO, and Hinton DR. Recombinant human VEGF165b inhibits experimental choroidal neovascularization. Invest Ophthalmol Vis Sci 51: 4282-4288, 2010.

115. Huang H, Langenkamp E, Georganaki M, Loskog A, Fuchs PF, Dieterich LC, Kreuger $\mathbf{J}$, and Dimberg $\mathbf{A}$. VEGF suppresses T-lymphocyte infiltration in the tumor microenvironment through inhibition of NF-kappaB-induced endothelial activation. Faseb $\mathrm{J} 29$ : 227-238, 2015.

116. Hudson N, Powner MB, Sarker MH, Burgoyne T, Campbell M, Ockrim ZK, Martinelli R, Futter CE, Grant MB, Fraser PA, Shima DT, Greenwood J, and Turowski P. Differential apicobasal VEGF signaling at vascular blood-neural barriers. Dev Cell 30: 541-552, 2014.

117. Hulse R, Wynick D, and Donaldson L. Intact cutaneous C fibre afferent properties in mechanical and cold neuropathic allodynia. European journal of pain 14: 565, 2010.

118. Hulse RP, Beazley-Long N, Hua J, Kennedy H, Prager J, Bevan H, Qiu Y, Fernandes ES, Gammons MV, Ballmer-Hofer K, Gittenberger de Groot AC, Churchill AJ, Harper SJ, Brain SD, Bates DO, and Donaldson LF. Regulation of alternative VEGF-A mRNA splicing is a therapeutic target for analgesia. Neurobiology of disease 71: 245-259, 2014.

119. Hulse RP, Beazley-Long N, Ved N, Bestall SM, Riaz H, Singhal P, Ballmer Hofer K, Harper SJ, Bates D, and Donaldson LF. Vascular endothelial growth factor-A165b prevents diabetic neuropathic pain and sensory neuronal degeneration. Clin Sci 129: 741-756, 2015.

120. Hulse RP, Drake RA, Bates DO, and Donaldson LF. The control of alternative splicing by SRSF1 in myelinated afferents contributes to the development of neuropathic pain. Neurobiology of disease 96: 186-200, 2016.

121. Ichimura K, Stan RV, Kurihara H, and Sakai T. Glomerular endothelial cells form diaphragms during development and pathologic conditions. J Am Soc Nephrol 19: 1463-1471, 2008.

122. Inan UU, Avci B, Kusbeci T, Kaderli B, Avci R, and Temel SG. Preclinical safety evaluation of intravitreal injection of full-length humanized vascular endothelial growth factor antibody in rabbit eyes. Invest Ophthalmol Vis Sci 48: 1773-1781, 2007.

123. Ishida A, Murray J, Saito Y, Kanthou C, Benzakour O, Shibuya M, and Wijelath ES. Expression of vascular endothelial growth factor receptors in smooth muscle cells. J Cell Physiol 188: 359-368, 2001.

124. Jabbour HN, Boddy SC, and Lincoln GA. Pattern and localisation of expression of vascular endothelial growth factor and its receptor flt-1 in the ovine pituitary gland: expression is independent of hypothalamic control. Mol Cell Endocrinol 134: 91-100, 1997.

125. Janer J, Andersson S, Haglund C, Karikoski R, and Lassus P. Placental growth factor and vascular endothelial growth factor receptor-2 in human lung development. Pediatrics 122: 340-346, 2008.

126. Janer J, Lassus P, Haglund C, Paavonen K, Alitalo K, and Andersson S. Pulmonary vascular endothelial growth factor- $C$ in development and lung injury in preterm infants. $A m \mathrm{~J}$ Respir Crit Care Med 174: 326-330, 2006.

127. Jia H, Bagherzadeh A, Bicknell R, Duchen MR, Liu D, and Zachary I. Vascular endothelial growth factor (VEGF)-D and VEGF-A differentially regulate KDR-mediated signaling and biological function in vascular endothelial cells. J Biol Chem 279: 36148-36157, 2004.

128. Jin K, Zhu Y, Sun Y, Mao XO, Xie L, and Greenberg DA. Vascular endothelial growth factor (VEGF) stimulates neurogenesis in vitro and in vivo. Proc Natl Acad Sci U S A 99: 1194611950, 2002.

129. Jin KL, Mao XO, and Greenberg DA. Vascular endothelial growth factor rescues HN33 neural cells from death induced by serum withdrawal. J Mol Neurosci 14: 197-203, 2000. 
130. Jin KL, Mao XO, Nagayama T, Goldsmith PC, and Greenberg DA. Induction of vascular endothelial growth factor and hypoxia-inducible factor-1alpha by global ischemia in rat brain. Neuroscience 99: 577-585, 2000.

131. Joory KD, Levick JR, Mortimer PS, and Bates DO. Vascular endothelial growth factorC (VEGF-C) expression in normal human tissues. Lymphat Res Biol 4: 73-82, 2006.

132. Kaner RJ and Crystal RG. Compartmentalization of vascular endothelial growth factor to the epithelial surface of the human lung. Mol Med 7: 240-246, 2001.

133. Karpanen T, Bry M, Ollila HM, Seppanen-Laakso T, Liimatta E, Leskinen H, Kivela R, Helkamaa T, Merentie M, Jeltsch M, Paavonen K, Andersson LC, Mervaala E, Hassinen IE, Yla-Herttuala S, Oresic M, and Alitalo K. Overexpression of vascular endothelial growth factor-B in mouse heart alters cardiac lipid metabolism and induces myocardial hypertrophy. Circ Res 103: 1018-1026, 2008.

134. Kasahara Y, Tuder RM, Taraseviciene-Stewart L, Le Cras TD, Abman S, Hirth PK, Waltenberger J, and Voelkel NF. Inhibition of VEGF receptors causes lung cell apoptosis and emphysema. J Clin Invest 106: 1311-1319., 2000.

135. Kaur C, Foulds WS, and Ling EA. Blood-retinal barrier in hypoxic ischaemic conditions: basic concepts, clinical features and management. Prog Retin Eye Res 27: 622-647, 2008.

136. Kawamura H, Li X, Harper SJ, Bates DO, and Claesson-Welsh L. Vascular endothelial growth factor (VEGF)-A165b is a weak in vitro agonist for VEGF receptor-2 due to lack of coreceptor binding and deficient regulation of kinase activity. Cancer Res 68: 4683-4692, 2008.

137. Kearns MT, Dalal S, Horstmann SA, Richens TR, Tanaka T, Doe JM, Boe DM, Voelkel NF, Taraseviciene-Stewart L, Janssen WJ, Lee CG, Elias JA, Bratton D, Tuder RM, Henson PM, and Vandivier RW. Vascular endothelial growth factor enhances macrophage clearance of apoptotic cells. Am J Physiol Lung Cell Mol Physiol 302: L711-718, 2012.

138. Kent DL. Age-related macular degeneration: beyond anti-angiogenesis. Mol Vis 20: 4655, 2014.

139. Kikuchi R, Nakamura K, MacLauchlan S, Ngo DT, Shimizu I, Fuster JJ, Katanasaka Y, Yoshida S, Qiu Y, Yamaguchi TP, Matsushita T, Murohara T, Gokce N, Bates DO, Hamburg NM, and Walsh K. An antiangiogenic isoform of VEGF-A contributes to impaired vascularization in peripheral artery disease. Nat Med, 2014.

140. Kikuchi R, Nakamura K, MacLauchlan S, Ngo DT, Shimizu I, Fuster JJ, Katanasaka Y, Yoshida S, Qiu Y, Yamaguchi TP, Matsushita T, Murohara T, Gokce N, Bates DO, Hamburg NM, and Walsh K. An antiangiogenic isoform of VEGF-A contributes to impaired vascularization in peripheral artery disease. Nat Med 20: 1464-1471, 2014.

141. Kim JH, Kim C, Lee BJ, Yu YS, Park KH, and Kim KW. Absence of intravitreal bevacizumab-induced neuronal toxicity in the retina. Neurotoxicology 29: 1131-1135, 2008.

142. Kim S, Kim YJ, Kim NR, and Chin HS. Effects of Bevacizumab on Bcl-2 Expression and Apoptosis in Retinal Pigment Epithelial Cells under Oxidative Stress. Korean J Ophthalmol 29: 424-432, 2015.

143. Kirby ED, Kuwahara AA, Messer RL, and Wyss-Coray T. Adult hippocampal neural stem and progenitor cells regulate the neurogenic niche by secreting VEGF. Proc Natl Acad Sci U S A 112: 4128-4133, 2015.

144. Kishuku M, Nishioka Y, Abe S, Kishi J, Ogino H, Aono Y, Azuma M, Kinoshita K, Batmunkh R, Makino H, Ranjan P, Minakuchi K, and Sone S. Expression of soluble vascular endothelial growth factor receptor-1 in human monocyte-derived mature dendritic cells contributes to their antiangiogenic property. J Immunol 183: 8176-8185, 2009.

145. Kivela R, Bry M, Robciuc MR, Rasanen M, Taavitsainen M, Silvola JM, Saraste A, Hulmi JJ, Anisimov A, Mayranpaa MI, Lindeman JH, Eklund L, Hellberg S, Hlushchuk R, Zhuang ZW, Simons M, Djonov V, Knuuti J, Mervaala E, and Alitalo K. VEGF-B-induced vascular growth leads to metabolic reprogramming and ischemia resistance in the heart. EMBO molecular medicine 6: 307-321, 2014.

146. Knapp AE, Goldberg D, Delavar H, Trisko BM, Tang K, Hogan MC, Wagner PD, and Breen EC. Skeletal myofiber VEGF regulates contraction-induced perfusion and exercise capacity but not muscle capillarity in adult mice. Am J Physiol Regul Integr Comp Physiol 311: R192-199, 2016. 
147. Ku DD, Zaleski JK, Liu S, and Brock TA. Vascular endothelial growth factor induces EDRF-dependent relaxation in coronary arteries. Am J Physiol 265: H586-592, 1993.

148. Kuhn H, Kruger S, Hammerschmidt S, and Wirtz H. High concentrations of vascular endothelial growth factor reduce stretch-induced apoptosis of alveolar type II cells. Respirology 15: 343-348, 2010.

149. Kwak N, Okamoto N, Wood JM, and Campochiaro PA. VEGF is major stimulator in model of choroidal neovascularization. Invest Ophthalmol Vis Sci 41: 3158-3164, 2000.

150. Lambrechts D, Storkebaum E, Morimoto M, Del-Favero J, Desmet F, Marklund SL, Wyns S, Thijs V, Andersson J, van Marion I, Al-Chalabi A, Bornes S, Musson R, Hansen V, Beckman L, Adolfsson R, Pall HS, Prats H, Vermeire S, Rutgeerts P, Katayama S, Awata T, Leigh N, Lang-Lazdunski L, Dewerchin M, Shaw C, Moons L, Vlietinck R, Morrison KE, Robberecht W, Van Broeckhoven C, Collen D, Andersen PM, and Carmeliet P. VEGF is a modifier of amyotrophic lateral sclerosis in mice and humans and protects motoneurons against ischemic death. Nat Genet 34: 383-394, 2003.

151. Lang-Lazdunski L, Matsushita K, Hirt L, Waeber C, Vonsattel JP, Moskowitz MA, and Dietrich WD. Spinal cord ischemia. Development of a model in the mouse. Stroke 31: 208213, 2000.

152. Langlet F, Levin BE, Luquet S, Mazzone M, Messina A, Dunn-Meynell AA, Balland E, Lacombe A, Mazur D, Carmeliet P, Bouret SG, Prevot V, and Dehouck B. Tanycytic VEGFA boosts blood-hypothalamus barrier plasticity and access of metabolic signals to the arcuate nucleus in response to fasting. Cell metabolism 17: 607-617, 2013.

153. Le Cras TD, Spitzmiller RE, Albertine KH, Greenberg JM, Whitsett JA, and Akeson AL. VEGF causes pulmonary hemorrhage, hemosiderosis, and air space enlargement in neonatal mice. Am J Physiol Lung Cell Mol Physiol 287: L134-142, 2004.

154. Lee DW, Miyasato LE, and Clayton NS. Neurobiological bases of spatial learning in the natural environment: neurogenesis and growth in the avian and mammalian hippocampus. Neuroreport 9: R15-27, 1998.

155. Lee $\mathbf{E}$ and Son $\mathbf{H}$. Adult hippocampal neurogenesis and related neurotrophic factors. BMB Rep 42: 239-244, 2009.

156. Lee S, Chen TT, Barber CL, Jordan MC, Murdock J, Desai S, Ferrara N, Nagy A, Roos KP, and Iruela-Arispe ML. Autocrine VEGF signaling is required for vascular homeostasis. Cell 130: 691-703, 2007.

157. Leung DW, Cachianes G, Kuang WJ, Goeddel DV, and Ferrara N. Vascular endothelial growth factor is a secreted angiogenic mitogen. Science 246: 1306-1309, 1989.

158. Li M, Scott DE, Shandas R, Stenmark KR, and Tan W. High pulsatility flow induces adhesion molecule and cytokine mRNA expression in distal pulmonary artery endothelial cells. Ann Biomed Eng 37: 1082-1092, 2009.

159. Licht T, Goshen I, Avital A, Kreisel T, Zubedat S, Eavri R, Segal M, Yirmiya R, and Keshet E. Reversible modulations of neuronal plasticity by VEGF. Proc Natl Acad Sci U S A 108: 5081-5086, 2011.

160. Lieberwirth C, Pan Y, Liu Y, Zhang Z, and Wang Z. Hippocampal adult neurogenesis: Its regulation and potential role in spatial learning and memory. Brain Res 1644: 127-140, 2016.

161. Lin J, Li G, Den X, Xu C, Liu S, Gao Y, Liu H, Zhang J, Li X, and Liang S. VEGF and its receptor-2 involved in neuropathic pain transmission mediated by $\mathrm{P} 2 \mathrm{X}(2)(/)(3)$ receptor of primary sensory neurons. Brain Res Bull 83: 284-291, 2010.

162. Lincoln GA and Clarke IJ. Photoperiodically-induced cycles in the secretion of prolactin in hypothalamo-pituitary disconnected rams: evidence for translation of the melatonin signal in the pituitary gland. J Neuroendocrinol 6: 251-260, 1994.

163. Liu S, Xu C, Li G, Liu H, Xie J, Tu G, Peng H, Qiu S, and Liang S. Vatalanib decrease the positive interaction of VEGF receptor-2 and $\mathrm{P} 2 \mathrm{X} 2 / 3$ receptor in chronic constriction injury rats. Neurochemistry international 60: 565-572, 2012.

164. Lloyd PG, Prior BM, Li H, Yang HT, and Terjung RL. VEGF receptor antagonism blocks arteriogenesis, but only partially inhibits angiogenesis, in skeletal muscle of exercisetrained rats. Am J Physiol Heart \& Circ 288: H759-768, 2005.

165. Louissaint A, Jr., Rao S, Leventhal C, and Goldman SA. Coordinated interaction of neurogenesis and angiogenesis in the adult songbird brain. Neuron 34: 945-960, 2002. 
166. Lunn JS, Sakowski SA, Kim B, Rosenberg AA, and Feldman EL. Vascular endothelial growth factor prevents G93A-SOD1-induced motor neuron degeneration. Dev Neurobiol 69: 871884, 2009.

167. Magnussen AL, Rennel ES, Hua J, Bevan HS, Beazley Long N, Lehrling C, Gammons M, Floege J, Harper SJ, Agostini HT, Bates DO, and Churchill AJ. VEGF-A165b is cytoprotective and antiangiogenic in the retina. Invest Ophthalmol Vis Sci 51: 4273-4281, 2010.

168. Maharaj AS and D'Amore PA. Roles for VEGF in the adult. Microvasc Res 74: 100-113, 2007.

169. Makinen T, Jussila L, Veikkola T, Karpanen T, Kettunen MI, Pulkkanen KJ, Kauppinen R, Jackson DG, Kubo H, Nishikawa S, Yla-Herttuala S, and Alitalo K. Inhibition of lymphangiogenesis with resulting lymphedema in transgenic mice expressing soluble VEGF receptor-3. Nat Med 7: 199-205, 2001.

170. Malykhina AP, Lei Q, Erickson CS, Epstein ML, Saban MR, Davis CA, and Saban R. VEGF induces sensory and motor peripheral plasticity, alters bladder function, and promotes visceral sensitivity. BMC Physiol 12: 15, 2012.

171. Manetti M, Guiducci S, Romano E, Ceccarelli C, Bellando-Randone S, Conforti ML, Ibba-Manneschi L, and Matucci-Cerinic M. Overexpression of VEGF165b, an Inhibitory Splice Variant of Vascular Endothelial Growth Factor, Leads to Insufficient Angiogenesis in Patients With Systemic Sclerosis. Circ Res 109: :e14-26, 2011.

172. Maniscalco WM, Watkins RH, D'Angio CT, and Ryan RM. Hyperoxic injury decreases alveolar epithelial cell expression of vascular endothelial growth factor (VEGF) in neonatal rabbit lung. Am J Respir Cell Mol Biol 16: 557-567, 1997.

173. Marneros AG, Fan J, Yokoyama Y, Gerber HP, Ferrara N, Crouch RK, and Olsen BR. Vascular endothelial growth factor expression in the retinal pigment epithelium is essential for choriocapillaris development and visual function. Am J Pathol 167: 1451-1459, 2005.

174. Matsuoka A, Maeda O, Mizutani T, Nakano Y, Tsunoda N, Kikumori T, Goto H, and Ando Y. Bevacizumab Exacerbates Paclitaxel-Induced Neuropathy: A Retrospective Cohort Study. PLoS One 11: e0168707, 2016.

175. Matsuzaki H, Tamatani M, Yamaguchi A, Namikawa K, Kiyama H, Vitek MP, Mitsuda $\mathbf{N}$, and Tohyama $\mathbf{M}$. Vascular endothelial growth factor rescues hippocampal neurons from glutamate-induced toxicity: signal transduction cascades. Faseb J 15: 1218-1220, 2001.

176. Medford AR, Douglas SK, Godinho SI, Uppington KM, Armstrong L, Gillespie KM, van Zyl B, Tetley TD, Ibrahim NB, and Millar AB. Vascular Endothelial Growth Factor (VEGF) isoform expression and activity in human and murine lung injury. Respiratory research 10: 27, 2009.

177. Medford AR, Ibrahim NB, and Millar AB. Vascular endothelial growth factor receptor and coreceptor expression in human acute respiratory distress syndrome. Journal of critical care 24: 236-242, 2009.

178. Medford AR and Millar AB. Vascular endothelial growth factor (VEGF) in acute lung injury (ALI) and acute respiratory distress syndrome (ARDS): paradox or paradigm? Thorax 61: 621-626, 2006.

179. Merdzhanova G, Gout S, Keramidas M, Edmond V, Coll JL, Brambilla C, Brambilla E, Gazzeri S, and Eymin B. The transcription factor E2F1 and the SR protein SC35 control the ratio of pro-angiogenic versus antiangiogenic isoforms of vascular endothelial growth factor-A to inhibit neovascularization in vivo. Oncogene 29: 5392-5403, 2010.

180. Milkiewicz M, Hudlicka O, Verhaeg J, Egginton S, and Brown MD. Differential expression of Flk-1 and Flt-1 in rat skeletal muscle in response to chronic ischaemia: favourable effect of muscle activity. Clin Sci (Lond) 105: 473-482, 2003.

181. Miner JH. Glomerular basement membrane composition and the filtration barrier. Pediatr Nephrol 26: 1413-1417, 2011.

182. Miyamoto K, Khosrof S, Bursell SE, Moromizato Y, Aiello LP, Ogura Y, and Adamis AP. Vascular endothelial growth factor (VEGF)-induced retinal vascular permeability is mediated by intercellular adhesion molecule-1 (ICAM-1). Am J Pathol 156: 1733-1739, 2000.

183. Monacci WT, Merrill MJ, and Oldfield EH. Expression of vascular permeability factor/vascular endothelial growth factor in normal rat tissues. Am J Physiol 264: C995-1002, 1993. 
184. Mortara L, Benest AV, Bates DO, and Noonan DM. Can the co-dependence of the immune system and angiogenesis facilitate pharmacological targeting of tumours? Curr Opin Pharmacol 35: 66-74, 2017.

185. Mukhopadhyay D, Knebelmann B, Cohen HT, Ananth S, and Sukhatme VP. The von Hippel-Lindau tumor suppressor gene product interacts with Sp1 to repress vascular endothelial growth factor promoter activity. Mol Cell Biol 17: 5629-5639, 1997.

186. Mulder SF, Bertens D, Desar IM, Vissers KC, Mulders PF, Punt CJ, van Spronsen DJ, Langenhuijsen JF, Kessels RP, and van Herpen CM. Impairment of cognitive functioning during Sunitinib or Sorafenib treatment in cancer patients: a cross sectional study. BMC Cancer 14: 219, 2014.

187. Muller WA. The regulation of transendothelial migration: new knowledge and new questions. Cardiovasc Res 107: 310-320, 2015.

188. Mura M, Binnie M, Han B, Li C, Andrade CF, Shiozaki A, Zhang Y, Ferrara N, Hwang D, Waddell TK, Keshavjee S, and Liu M. Functions of type II pneumocyte-derived vascular endothelial growth factor in alveolar structure, acute inflammation, and vascular permeability. Am J Pathol 176: 1725-1734, 2010.

189. Mura M, Han B, Andrade CF, Seth R, Hwang D, Waddell TK, Keshavjee S, and Liu M. The early responses of VEGF and its receptors during acute lung injury: implication of VEGF in alveolar epithelial cell survival. Critical care 10: R130, 2006.

190. Murakami T, Arai M, Sunada Y, and Nakamura A. VEGF 164 gene transfer by electroporation improves diabetic sensory neuropathy in mice. J Gene Med 8: 773-781, 2006.

191. Murrant CL and Sarelius IH. Coupling of muscle metabolism and muscle blood flow in capillary units during contraction. Acta Physiol Scand 168: 531-541, 2000.

192. Nadaud S, Philippe M, Arnal JF, Michel JB, and Soubrier F. Sustained increase in aortic endothelial nitric oxide synthase expression in vivo in a model of chronic high blood flow. Circ Res 79: 857-863, 1996.

193. Neal CR, Crook H, Bell E, Harper SJ, and Bates DO. Three-dimensional reconstruction of glomeruli by electron microscopy reveals a distinct restrictive urinary subpodocyte space. $\mathrm{J} A m$ Soc Nephrol 16: 1223-1235, 2005.

194. Neal CR, Muston PR, Njegovan D, Verrill R, Harper SJ, Deen WM, and Bates DO. Glomerular filtration into the subpodocyte space is highly restricted under physiological perfusion conditions. Am J Physiol Renal Physiol 293: F1787-1798, 2007.

195. Nesic O, Sundberg LM, Herrera JJ, Mokkapati VU, Lee J, and Narayana PA. Vascular endothelial growth factor and spinal cord injury pain. Journal of neurotrauma 27: 1793-1803, 2010.

196. Neufeld G, Cohen T, Gengrinovitch S, and Poltorak Z. Vascular endothelial growth factor (VEGF) and its receptors. Faseb J 13: 9-22, 1999.

197. Nowak DG, Amin EM, Rennel ES, Hoareau-Aveilla C, Gammons M, Damodoran G, Hagiwara M, Harper SJ, Woolard J, Ladomery MR, and Bates DO. Regulation of vascular endothelial growth factor (VEGF) splicing from pro-angiogenic to anti-angiogenic isoforms: a novel therapeutic strategy for angiogenesis. J Biol Chem 285: 5532-5540, 2010.

198. Nowak DG, Woolard J, Amin EM, Konopatskaya O, Saleem MA, Churchill AJ, Ladomery MR, Harper SJ, and Bates DO. Expression of pro- and anti-angiogenic isoforms of VEGF is differentially regulated by known splicing and growth factors. . J Cell Sci 121: 34873495, 2008.

199. Noy P, Sawasdichai A, Jayaraman PS, and Gaston K. Protein kinase CK2 inactivates $\mathrm{PRH} /$ Hhex using multiple mechanisms to de-repress VEGF-signalling genes and promote cell survival. Nucleic acids research 40: 9008-9020, 2012.

200. Noy P, Williams H, Sawasdichai A, Gaston K, and Jayaraman PS. PRH/Hhex controls cell survival through coordinate transcriptional regulation of vascular endothelial growth factor signaling. Mol Cell Biol 30: 2120-2134, 2010.

201. Obeidat M, Obeidat M, and Ballermann BJ. Glomerular endothelium: a porous sieve and formidable barrier. Exp Cell Res 318: 964-972, 2012.

202. Oh DH, Kim BW, Choi M, Lee G, Choi JS, and Hyeon S. Changes in vascular endothelial growth factor (VEGF) induced by the Morris water maze task. Molecules and cells 33: 295-300, 2012. 
203. Olenich SA, Audet GN, Roberts KA, and Olfert IM. Effects of detraining on the temporal expression of positive and negative angioregulatory proteins in skeletal muscle of mice. J Physiol (Lond) 592: 3325-3338, 2014.

204. Olfert IM, Baum O, Hellsten Y, and Egginton S. Advances and challenges in skeletal muscle angiogenesis. Am J Physiol Heart \& Circ 310: H326-336, 2016.

205. Olfert IM, Howlett RA, Tang K, Dalton ND, Gu Y, Peterson KL, Wagner PD, and Breen EC. Muscle-specific VEGF deficiency greatly reduces exercise endurance in mice. $J$ Physiol (Lond) 587: 1755-1767, 2009.

206. Olfert IM, Howlett RA, Wagner PD, and Breen EC. Myocyte vascular endothelial growth factor is required for exercise-induced skeletal muscle angiogenesis. Am J Physiol Regul Integr Comp Physiol 299: R1059-1067, 2010.

207. Oltean S, Neal CR, Mavrou A, Patel P, Ahad T, Alsop C, Lee T, Sison K, Qiu Y, Harper SJ, Bates DO, and Salmon AH. VEGF165b overexpression restores normal glomerular water permeability in VEGF164-overexpressing adult mice. Am J Physiol Renal Physiol 303: F1026-1036, 2012.

208. Oltean S, Qiu Y, Ferguson JK, Stevens M, Neal C, Russell A, Kaura A, Arkill KP, Harris K, Symonds C, Lacey K, Wijeyaratne L, Gammons M, Wylie E, Hulse RP, Alsop C, Cope G, Damodaran G, Betteridge KB, Ramnath R, Satchell SC, Foster RR, Ballmer-Hofer K, Donaldson LF, Barratt J, Baelde HJ, Harper SJ, Bates DO, and Salmon AH. Vascular Endothelial Growth Factor-A165b Is Protective and Restores Endothelial Glycocalyx in Diabetic Nephropathy. J Am Soc Nephrol 26: 1889-1904, 2015.

209. Onions K, Betteridge KB, Buckner NR, Gamez M, Bates DO, Welsh GI, Satchell SC, and Foster RR. VEGF-C as an anti-albuminuric agent. British Microcirculation Society Annual Meeting, Birmingham, UK. Microcirculation, 2017.

210. Oosthuyse B, Moons L, Storkebaum E, Beck H, Nuyens D, Brusselmans K, Van Dorpe J, Hellings P, Gorselink M, Heymans S, Theilmeier G, Dewerchin M, Laudenbach V, Vermylen P, Raat H, Acker T, Vleminckx V, Van Den Bosch L, Cashman N, Fujisawa H, Drost MR, Sciot R, Bruyninckx F, Hicklin DJ, Ince C, Gressens P, Lupu F, Plate KH, Robberecht W, Herbert JM, Collen D, and Carmeliet P. Deletion of the hypoxia-response element in the vascular endothelial growth factor promoter causes motor neuron degeneration. Nat Genet 28: 131-138, 2001.

211. Park JE, Chen HH, Winer J, Houck KA, and Ferrara N. Placenta growth factor. Potentiation of vascular endothelial growth factor bioactivity, in vitro and in vivo, and high affinity binding to Flt-1 but not to Flk-1/KDR. J Biol Chem 269: 25646-25654, 1994.

212. Park SH, Kim KW, Lee YS, Baek JH, Kim MS, Lee YM, Lee MS, and Kim YJ. Hypoglycemia-induced VEGF expression is mediated by intracellular $\mathrm{Ca} 2+$ and protein kinase $\mathrm{C}$ signaling pathway in HepG2 human hepatoblastoma cells. Int J Mol Med 7: 91-96, 2001.

213. Parmar KM, Larman HB, Dai G, Zhang Y, Wang ET, Moorthy SN, Kratz JR, Lin Z, Jain MK, Gimbrone MA, Jr., and Garcia-Cardena G. Integration of flow-dependent endothelial phenotypes by Kruppel-like factor 2. J Clin Invest 116: 49-58, 2006.

214. Pati S, Orsi SA, Moore AN, and Dash PK. Intra-hippocampal administration of the VEGF receptor blocker PTK787/ZK222584 impairs long-term memory. Brain Res 1256: 85-91, 2009.

215. Perrin RM KO, Qiu Y, Harper S, Bates DO, Churchill AJ. Diabetic retinopathy is associated with a switch in splicing from anti- to pro-angiogenic isoforms of vascular endothelial growth factor. Diabetologia 48, 2005.

216. Perrin RM, Konopatskaya O, Qiu Y, Harper S, Bates DO, and Churchill AJ. Diabetic retinopathy is associated with a switch in splicing from anti- to pro-angiogenic isoforms of vascular endothelial growth factor. Diabetologia 48: 2422-2427, 2005.

217. Peters S, Heiduschka P, Julien S, Ziemssen F, Fietz H, Bartz-Schmidt KU, and Schraermeyer $\mathbf{U}$. Ultrastructural findings in the primate eye after intravitreal injection of bevacizumab. Am J Ophthalmol 143: 995-1002, 2007.

218. Popa GT and Fielding U. The vascular link between the pituitary and the hypothalamus. Lancet 219: 238-240, 1930.

219. Prevot V, Croix D, Bouret S, Dutoit S, Tramu G, Stefano GB, and Beauvillain JC. Definitive evidence for the existence of morphological plasticity in the external zone of the median 
eminence during the rat estrous cycle: implication of neuro-glio-endothelial interactions in gonadotropin-releasing hormone release. Neuroscience 94: 809-819, 1999.

220. Qiu Y, Ferguson J, Oltean S, Neal CR, Kaura A, Bevan H, Wood E, Sage LM, Lanati S, Nowak DG, Salmon AH, Bates D, and Harper SJ. Overexpression of VEGF165b in podocytes reduces glomerular permeability. J Am Soc Nephrol 21: 1498-1509, 2010.

221. Rai S, Nejadhamzeeigilani Z, Gutowski NJ, and Whatmore JL. Loss of the endothelial glycocalyx is associated with increased E-selectin mediated adhesion of lung tumour cells to the brain microvascular endothelium. J Exp Clin Cancer Res 34: 105, 2015.

222. Real-Hohn A, Zancan P, Da Silva D, Martins ER, Salgado LT, Mermelstein CS, Gomes AM, and Sola-Penna M. Filamentous actin and its associated binding proteins are the stimulatory site for 6-phosphofructo-1-kinase association within the membrane of human erythrocytes. Biochimie 92: 538-544, 2010.

223. Reeson P, Tennant KA, Gerrow K, Wang J, Weiser Novak S, Thompson K, Lockhart KL, Holmes A, Nahirney PC, and Brown CE. Delayed inhibition of VEGF signaling after stroke attenuates blood-brain barrier breakdown and improves functional recovery in a comorbiditydependent manner. The Journal of neuroscience : the official journal of the Society for Neuroscience 35: 5128-5143, 2015.

224. Robciuc MR, Kivela R, Williams IM, de Boer JF, van Dijk TH, Elamaa H, TigistuSahle F, Molotkov D, Leppanen VM, Kakela R, Eklund L, Wasserman DH, Groen AK, and Alitalo K. VEGFB/VEGFR1-Induced Expansion of Adipose Vasculature Counteracts Obesity and Related Metabolic Complications. Cell metabolism 23: 712-724, 2016.

225. Roberts JR, Perkins GD, Fujisawa T, Pettigrew KA, Gao F, Ahmed A, and Thickett DR. Vascular endothelial growth factor promotes physical wound repair and is anti-apoptotic in primary distal lung epithelial and A549 cells. Crit Care Med 35: 2164-2170, 2007.

226. Roberts WG and Palade GE. Increased microvascular permeability and endothelial fenestration induced by vascular endothelial growth factor. J Cell Sci 108: 2369-2379, 1995.

227. Ropper AH, Gorson KC, Gooch CL, Weinberg DH, Pieczek A, Ware JH, Kershen J, Rogers A, Simovic D, Schratzberger P, Kirchmair R, and Losordo D. Vascular endothelial growth factor gene transfer for diabetic polyneuropathy: a randomized, double-blinded trial. Ann Neurol 65: 386-393, 2009.

228. Ruhrberg C, Gerhardt H, Golding M, Watson R, loannidou S, Fujisawa H, Betsholtz C, and Shima DT. Spatially restricted patterning cues provided by heparin-binding VEGF-A control blood vessel branching morphogenesis. Genes Dev 16: 2684-2698, 2002.

229. Saaristo A, Veikkola T, Enholm B, Hytonen M, Arola J, Pajusola K, Turunen P, Jeltsch M, Karkkainen MJ, Kerjaschki D, Bueler H, Yla-Herttuala S, and Alitalo K. Adenoviral VEGF-C overexpression induces blood vessel enlargement, tortuosity, and leakiness but no sprouting angiogenesis in the skin or mucous membranes. Faseb J 16: 1041-1049., 2002.

230. Saint-Geniez M, Kurihara T, Sekiyama E, Maldonado AE, and D'Amore PA. An essential role for RPE-derived soluble VEGF in the maintenance of the choriocapillaris. Proc Natl Acad Sci U S A 106: 18751-18756, 2009.

231. Salmon AH, Neal CR, Bates DO, and Harper SJ. Vascular endothelial growth factor increases the ultrafiltration coefficient in isolated intact Wistar rat glomeruli. J Physiol 570: 141156, 2006.

232. Salmon AH, Toma I, Sipos A, Muston PR, Harper SJ, Bates DO, Neal CR, and PetiPeterdi J. Evidence for restriction of fluid and solute movement across the glomerular capillary wall by the subpodocyte space. Am J Physiol Renal Physiol 293: F1777-1786, 2007.

233. Sarelius IH and Glading AJ. Control of vascular permeability by adhesion molecules. Tissue Barriers 3: e985954, 2015.

234. Satchell SC and Braet F. Glomerular endothelial cell fenestrations: an integral component of the glomerular filtration barrier. Am J Physiol Renal Physiol 296: F947-956, 2009.

235. Savin VJ and Terreros DA. Filtration in single isolated mammalian glomeruli. Kidney Int 20: 188-197, 1981.

236. Sawano A, Iwai S, Sakurai Y, Ito M, Shitara K, Nakahata T, and Shibuya M. Flt-1, vascular endothelial growth factor receptor 1 , is a novel cell surface marker for the lineage of monocyte-macrophages in humans. Blood 97: 785-791, 2001. 
237. Schoors S, De Bock K, Cantelmo AR, Georgiadou M, Ghesquiere B, Cauwenberghs S, Kuchnio A, Wong BW, Quaegebeur A, Goveia J, Bifari F, Wang X, Blanco R, Tembuyser B, Cornelissen I, Bouche A, Vinckier S, Diaz-Moralli S, Gerhardt H, Telang S, Cascante M, Chesney J, Dewerchin M, and Carmeliet P. Partial and transient reduction of glycolysis by PFKFB3 blockade reduces pathological angiogenesis. Cell metabolism 19: 37-48, 2014.

238. Schratzberger P, Walter DH, Rittig K, Bahlmann FH, Pola R, Curry C, Silver M, Krainin JG, Weinberg DH, Ropper AH, and Isner JM. Reversal of experimental diabetic neuropathy by VEGF gene transfer. J Clin Invest 107: 1083-1092, 2001.

239. Schumacher VA, Jeruschke S, Eitner F, Becker JU, Pitschke G, Ince Y, Miner JH, Leuschner I, Engers R, Everding AS, Bulla M, and Royer-Pokora B. Impaired glomerular maturation and lack of VEGF165b in Denys-Drash syndrome. J Am Soc Nephrol 18: 719-729, 2007.

240. Schwarte-Waldhoff I, Volpert OV, Bouck NP, Sipos B, Hahn SA, Klein-Scory S, Luttges J, Kloppel G, Graeven U, Eilert-Micus C, Hintelmann A, and Schmiegel W. Smad4/DPC4-mediated tumor suppression through suppression of angiogenesis. Proc Natl Acad Sci U S A 97: 9624-9629, 2000.

241. Schwenk RW, Luiken JJ, Bonen A, and Glatz JF. Regulation of sarcolemmal glucose and fatty acid transporters in cardiac disease. Cardiovasc Res 79: 249-258, 2008.

242. Selvaraj D, Gangadharan V, Michalski CW, Kurejova M, Stösser S, Srivastava K, Schweizerhof M, Waltenberger J, Ferrara N, Heppenstall P, Shibuya M, Augustin HG, and Kuner R. A Functional Role for VEGFR1 Expressed in Peripheral Sensory Neurons in Cancer Pain. Cancer cell 27: 780-796, 2015.

243. Semenza GL. HIF-1: using two hands to flip the angiogenic switch. Cancer Metastasis Rev 19: 59-65, 2000.

244. Shalaby F, Rossant J, Yamaguchi TP, Gertsenstein M, Wu XF, Breitman ML, and Schuh AC. Failure of blood-island formation and vasculogenesis in Flk-1-deficient mice. Nature 376: 62-66, 1995.

245. Shojaei F, Wu X, Malik AK, Zhong C, Baldwin ME, Schanz S, Fuh G, Gerber HP, and Ferrara N. Tumor refractoriness to anti-VEGF treatment is mediated by CD11b+Gr1+ myeloid cells. Nat Biotechnol 25: 911-920, 2007.

246. Shojaei F, Wu X, Zhong C, Yu L, Liang XH, Yao J, Blanchard D, Bais C, Peale FV, van Bruggen N, Ho C, Ross J, Tan M, Carano RA, Meng YG, and Ferrara N. Bv8 regulates myeloid-cell-dependent tumour angiogenesis. Nature 450: 825-831, 2007.

247. Shyy YJ, Hsieh HJ, Usami S, and Chien S. Fluid shear stress induces a biphasic response of human monocyte chemotactic protein 1 gene expression in vascular endothelium. Proc Natl Acad Sci U S A 91: 4678-4682, 1994.

248. Singh A, Satchell SC, Neal CR, McKenzie EA, Tooke JE, and Mathieson PW. Glomerular endothelial glycocalyx constitutes a barrier to protein permeability. J Am Soc Nephrol 18: 2885-2893, 2007.

249. Soker S, Fidder H, Neufeld G, and Klagsbrun M. Characterization of novel vascular endothelial growth factor (VEGF) receptors on tumor cells that bind VEGF165 via its exon 7encoded domain. J Biol Chem 271: 5761-5767, 1996.

250. Sondell $\mathbf{M}$ and Kanje $\mathbf{M}$. Postnatal expression of VEGF and its receptor flk-1 in peripheral ganglia. Neuroreport 12: 105-108, 2001.

251. Sondell M LG, Kanje M. Vascular endothelial growth factor has neurotrophic activity and stimulates axonal outgrowth, enhancing cell survival and Schwann cell proliferation in the peripheral nervous system. J Neurosci 19: 5731-5740, 1999.

252. Sondell M, Lundborg G, and Kanje M. Vascular endothelial growth factor has neurotrophic activity and stimulates axonal outgrowth, enhancing cell survival and Schwann cell proliferation in the peripheral nervous system. J Neurosci 19: 5731-5740, 1999.

253. Sondell M SF, Kanje M. Vascular endothelial growth factor is a neurotrophic factor which stimulates axonal outgrowth through the flk-1 receptor. Eur J Neurosci 12: 4243-4254, 2000.

254. Spitzer MS, Wallenfels-Thilo B, Sierra A, Yoeruek E, Peters S, Henke-Fahle S, BartzSchmidt KU, and Szurman P. Antiproliferative and cytotoxic properties of bevacizumab on different ocular cells. Br J Ophthalmol 90: 1316-1321, 2006. 
255. Steinberg RH, Wood I, and Hogan MJ. Pigment epithelial ensheathment and phagocytosis of extrafoveal cones in human retina. Philosophical transactions of the Royal Society of London Series B, Biological sciences 277: 459-474, 1977.

256. Stone OA, Carter JG, Lin PC, Paleolog E, Machado MJ, and Bates DO. Differential regulation of blood flow induced neovascularisation and mural cell recruitment by VEGF and angiopoietin signalling. J Physiol (Lond), 2016.

257. Storkebaum E, Lambrechts D, Dewerchin M, Moreno-Murciano MP, Appelmans S, Oh H, Van Damme P, Rutten B, Man WY, De Mol M, Wyns S, Manka D, Vermeulen K, Van Den Bosch L, Mertens N, Schmitz C, Robberecht W, Conway EM, Collen D, Moons L, and Carmeliet $\mathbf{P}$. Treatment of motoneuron degeneration by intracerebroventricular delivery of VEGF in a rat model of ALS. Nature neuroscience 8: 85-92, 2005.

258. Sugimoto H, Hamano Y, Charytan D, Cosgrove D, Kieran M, Sudhakar A, and Kalluri R. Neutralization of circulating vascular endothelial growth factor (VEGF) by anti-VEGF antibodies and soluble VEGF receptor 1 (sFIt-1) induces proteinuria. J Biol Chem 278: 1260512608, 2003.

259. Sun K, Wernstedt Asterholm I, Kusminski CM, Bueno AC, Wang ZV, Pollard JW, Brekken RA, and Scherer PE. Dichotomous effects of VEGF-A on adipose tissue dysfunction. Proc Natl Acad Sci U S A 109: 5874-5879, 2012.

260. Sun Y, Jin K, Xie L, Childs J, Mao XO, Logvinova A, and Greenberg DA. VEGFinduced neuroprotection, neurogenesis, and angiogenesis after focal cerebral ischemia. $\mathrm{J}$ Clin Invest 111: 1843-1851, 2003.

261. Takyar S, Vasavada H, Zhang JG, Ahangari F, Niu N, Liu Q, Lee CG, Cohn L, and Elias JA. VEGF controls lung Th2 inflammation via the miR-1-Mpl (myeloproliferative leukemia virus oncogene)-P-selectin axis. J Exp Med 210: 1993-2010, 2013.

262. Tammela T, Enholm B, Alitalo K, and Paavonen K. The biology of vascular endothelial growth factors. Cardiovasc Res 65: 550-563, 2005.

263. Tang K, Rossiter HB, Wagner PD, and Breen EC. Lung-targeted VEGF inactivation leads to an emphysema phenotype in mice. J Appl Physiol (1985) 97: 1559-1566; discussion 1549, 2004.

264. Taylor S, Trudeau D, Arnold B, Wang J, Gerrow K, Summerfeldt K, Holmes A, Zamani A, Brocardo P, and Brown C. VEGF can protect against blood brain barrier dysfunction, dendritic spine loss and spatial memory impairment in an experimental model of diabetes. Neurobiology of disease 78: 11, 2015.

265. Tesfaye S, Malik R, and Ward JD. Vascular factors in diabetic neuropathy. Diabetologia 37: 847-854, 1994.

266. Textor B, Sator-Schmitt M, Richter KH, Angel P, and Schorpp-Kistner M. C-Jun and JunB are essential for hypoglycemia-mediated VEGF induction. Annals of the New York Academy of Sciences 1091: 310-318, 2006.

267. Thaler S, Fiedorowicz M, Choragiewicz TJ, Bolz S, Tura A, Henke-Fahle S, Yoeruek E, Zrenner E, Bartz-Schmidt KU, Ziemssen F, and Schuettauf F. Toxicity testing of the VEGF inhibitors bevacizumab, ranibizumab and pegaptanib in rats both with and without prior retinal ganglion cell damage. Acta Ophthalmol 88: e170-176, 2010.

268. Thi MM, lacobas DA, lacobas S, and Spray DC. Fluid shear stress upregulates vascular endothelial growth factor gene expression in osteoblasts. Annals of the New York Academy of Sciences 1117: 73-81, 2007.

269. Tsantoulas C, Zhu L, Shaifta Y, Grist J, Ward JP, Raouf R, Michael GJ, and McMahon SB. Sensory neuron downregulation of the Kv9.1 potassium channel subunit mediates neuropathic pain following nerve injury. The Journal of neuroscience : the official journal of the Society for Neuroscience 32: 17502-17513, 2012.

270. Tsao PN, Su YN, Li H, Huang PH, Chien CT, Lai YL, Lee CN, Chen CA, Cheng WF, Wei SC, Yu CJ, Hsieh FJ, and Hsu SM. Overexpression of placenta growth factor contributes to the pathogenesis of pulmonary emphysema. Am J Respir Crit Care Med 169: 505-511, 2004.

271. Tschulakow A, Christner S, Julien S, Ludinsky M, van der Giet M, and Schraermeyer U. Effects of a single intravitreal injection of aflibercept and ranibizumab on glomeruli of monkeys. PLoS One 9: e113701, 2014. 
272. Tuder RM, Kasahara Y, and Voelkel NF. Inhibition of vascular endothelial growth factor receptors causes emphysema in rats. Chest 117: 281S, 2000.

273. Uchida C, Nwadozi E, Hasanee A, Olenich S, Olfert IM, and Haas TL. Muscle-derived vascular endothelial growth factor regulates microvascular remodelling in response to increased shear stress in mice. Acta physiologica 214: 349-360, 2015.

274. van Neerven S, Joosten EA, Brook GA, Lambert CA, Mey J, Weis J, Marcus MA, Steinbusch HW, van Kleef M, Patijn J, and Deumens R. Repetitive intrathecal VEGF(165) treatment has limited therapeutic effects after spinal cord injury in the rat. Journal of neurotrauma 27: 1781-1791, 2010.

275. Van Schaftingen E, Lederer B, Bartrons R, and Hers HG. A kinetic study of pyrophosphate: fructose-6-phosphate phosphotransferase from potato tubers. Application to a microassay of fructose 2,6-bisphosphate. European journal of biochemistry 129: 191-195, 1982.

276. Van Vught PW, Sutedja NA, Veldink JH, Koeleman BP, Groeneveld GJ, Wijmenga C, Uitdehaag BM, de Jong JM, Baas F, Wokke JH, and Van den Berg LH. Lack of association between VEGF polymorphisms and ALS in a Dutch population. Neurology 65: 1643-1645, 2005.

277. Varet J, Douglas SK, Gilmartin L, Medford AR, Bates DO, Harper SJ, and Millar AB. VEGF in the lung: a role for novel isoforms. Am J Physiol Lung Cell Mol Physiol 298: L768-774, 2010.

278. Ved N, Hulse RP, Bestall SM, Donaldson LF, Bainbridge JW, and Bates DO. Vascular endothelial growth factor-A165b ameliorates outer-retinal barrier and vascular dysfunction in the diabetic retina. Clin Sci (Lond), 2017.

279. Vencappa S, Donaldson LF, and Hulse RP. Cisplatin induced sensory neuropathy is prevented by vascular endothelial growth factor-A. American journal of translational research 7: 1032-1044, 2015.

280. Venneri MA, De Palma M, Ponzoni M, Pucci F, Scielzo C, Zonari E, Mazzieri R, Doglioni C, and Naldini L. Identification of proangiogenic TIE2-expressing monocytes (TEMs) in human peripheral blood and cancer. Blood 109: 5276-5285, 2007.

281. Verheyen A, Peeraer E, Nuydens R, Dhondt J, Poesen K, Pintelon I, Daniels A, Timmermans JP, Meert T, Carmeliet P, and Lambrechts D. Systemic anti-vascular endothelial growth factor therapies induce a painful sensory neuropathy. Brain : a journal of neurology 135: 2629-2641, 2012.

282. Veron D, Reidy K, Marlier A, Bertuccio C, Villegas G, Jimenez J, Kashgarian M, and Tufro A. Induction of podocyte VEGF164 overexpression at different stages of development causes congenital nephrosis or steroid-resistant nephrotic syndrome. Am J Pathol 177: 22252233, 2010.

283. Veron D, Reidy KJ, Bertuccio C, Teichman J, Villegas G, Jimenez J, Shen W, Kopp JB, Thomas DB, and Tufro A. Overexpression of VEGF-A in podocytes of adult mice causes glomerular disease. Kidney Int 77: 989-999, 2010.

284. Vestweber D. How leukocytes cross the vascular endothelium. Nat Rev Immunol 15: 692-704, 2015.

285. Vogel K, Kuhn J, Kleesiek K, and Gotting C. A novel ultra-sensitive method for the quantification of glycosaminoglycan disaccharides using an automated DNA sequencer. Electrophoresis 27: 1363-1367, 2006.

286. Wang Y, Kilic E, Kilic U, Weber B, Bassetti CL, Marti HH, and Hermann DM. VEGF overexpression induces post-ischaemic neuroprotection, but facilitates haemodynamic steal phenomena. Brain 128: 52-63, 2005.

287. Waters RE, Rotevatn S, Li P, Annex BH, and Yan Z. Voluntary running induces fiber type-specific angiogenesis in mouse skeletal muscle. Am J Physiol Cell Physiol 287: C13421348, 2004.

288. Weil EJ, Lemley KV, Mason CC, Yee B, Jones LI, Blouch K, Lovato T, Richardson M, Myers BD, and Nelson RG. Podocyte detachment and reduced glomerular capillary endothelial fenestration promote kidney disease in type 2 diabetic nephropathy. Kidney Int 82: 1010-1017, 2012.

289. Weinberger D, Fink-Cohen S, Gaton DD, Priel E, and Yassur Y. Non-retinovascular leakage in diabetic maculopathy. $\mathrm{Br} \mathrm{J}$ Ophthalmol 79: 728-731, 1995. 
290. Williams JL, Cartland D, Hussain A, and Egginton S. A differential role for nitric oxide in two forms of physiological angiogenesis in mouse. J Physiol 570: 445-454, 2006.

291. Williams JL, Cartland D, Rudge JS, and Egginton S. VEGF trap abolishes shear stress- and overload-dependent angiogenesis in skeletal muscle. Microcirculation 13: 499-509, 2006.

292. Winkler BS, Boulton ME, Gottsch JD, and Sternberg P. Oxidative damage and agerelated macular degeneration. Mol Vis 5: 32, 1999.

293. Woolard J, Wang WY, Bevan HS, Qiu Y, Morbidelli L, Pritchard-Jones RO, Cui TG, Sugiono M, Waine E, Perrin R, Foster R, Digby-Bell J, Shields JD, Whittles CE, Mushens RE, Gillatt DA, Ziche M, Harper SJ, and Bates DO. VEGF165b, an inhibitory vascular endothelial growth factor splice variant: mechanism of action, in vivo effect on angiogenesis and endogenous protein expression. Cancer Res 64: 7822-7835, 2004.

294. Wu WK, Llewellyn OP, Bates DO, Nicholson LB, and Dick AD. IL-10 regulation of macrophage VEGF production is dependent on macrophage polarisation and hypoxia. Immunobiology 215: 796-803, 2010.

295. Xu HZ, Song Z, Fu S, Zhu M, and Le YZ. RPE barrier breakdown in diabetic retinopathy: seeing is believing. Journal of ocular biology, diseases, and informatics 4: 83-92, 2011.

296. Yamamura T, Hirunagi K, Ebihara S, and Yoshimura T. Seasonal morphological changes in the neuro-glial interaction between gonadotropin-releasing hormone nerve terminals and glial endfeet in Japanese quail. Endocrinology 145: 4264-4267, 2004.

297. Yao JS, Shen F, Young WL, and Yang GY. Comparison of doxycycline and minocycline in the inhibition of VEGF-induced smooth muscle cell migration. Neurochem Int 50: 524-530, 2007.

298. Yeomans A, Thompson N, Castle-Miller J, Bates DO, and Tortonese DJ. Mechanisms underlying pituitary microvasculature remodelling in Thoroughbred horses during the annual reproductive cycle. . World Congress of Reproductive Biology, Edinburgh, UK., 2014.

299. Zachwieja NJ, O'Connell GC, Stricker JC, Allen J, Vona-Davis L, Bryner R, Mandler W, and Olfert IM. Loss of Adipocyte VEGF Impairs Endurance Exercise Capacity in Mice. Medicine and science in sports and exercise 47: 2329-2339, 2015.

300. Zhang F, Tang Z, Hou X, Lennartsson J, Li Y, Koch AW, Scotney P, Lee C, Arjunan P, Dong L, Kumar A, Rissanen TT, Wang B, Nagai N, Fons $P$, Fariss $R$, Zhang $Y$, Wawrousek E, Tansey G, Raber J, Fong GH, Ding H, Greenberg DA, Becker KG, Herbert JM, Nash A, Yla-Herttuala S, Cao Y, Watts RJ, and Li X. VEGF-B is dispensable for blood vessel growth but critical for their survival, and VEGF-B targeting inhibits pathological angiogenesis. Proc Natl Acad Sci U S A 106: 6152-6157, 2009.

301. Zhang L, Yu D, Hu M, Xiong S, Lang A, Ellis LM, and Pollock RE. Wild-type p53 suppresses angiogenesis in human leiomyosarcoma and synovial sarcoma by transcriptional suppression of vascular endothelial growth factor expression. Cancer Res 60: 3655-3661, 2000.

302. Zheng C, Nennesmo I, Fadeel B, and Henter JI. Vascular endothelial growth factor prolongs survival in a transgenic mouse model of ALS. Ann Neurol 56: 564-567, 2004.

303. Zhou Y, Bellingard V, Feng KT, McMaster M, and Fisher SJ. Human cytotrophoblasts promote endothelial survival and vascular remodeling through secretion of Ang2, PIGF, and VEGF-C. Dev Biol 263: 114-125, 2003. 